\title{
Mali: Technical Assistance Report: Continued Modernization of the Malian Tax System and Administration
}

This technical assistance report on Mali was prepared by a staff team of the International Monetary Fund as background documentation for the periodic consultation with the member country. It is based on the information available at the time it was completed in August 2013. The views expressed in this document are those of the staff team and do not necessarily reflect the views of the government of Mali or the Executive Board of the IMF.

The policy of publication of staff reports and other documents by the IMF allows for the deletion of market-sensitive information.

Copies of this report are available to the public from

International Monetary Fund • Publication Services

$70019^{\text {th }}$ Street, N.W. • Washington, D.C. 20431

Telephone: (202) 623-7430 • Telefax: (202) 623-7201

E-mail: publications@imf.org Internet: http://www.imf.org

Price: $\$ 18.00$ a copy

\section{International Monetary Fund}

Washington, D.C. 


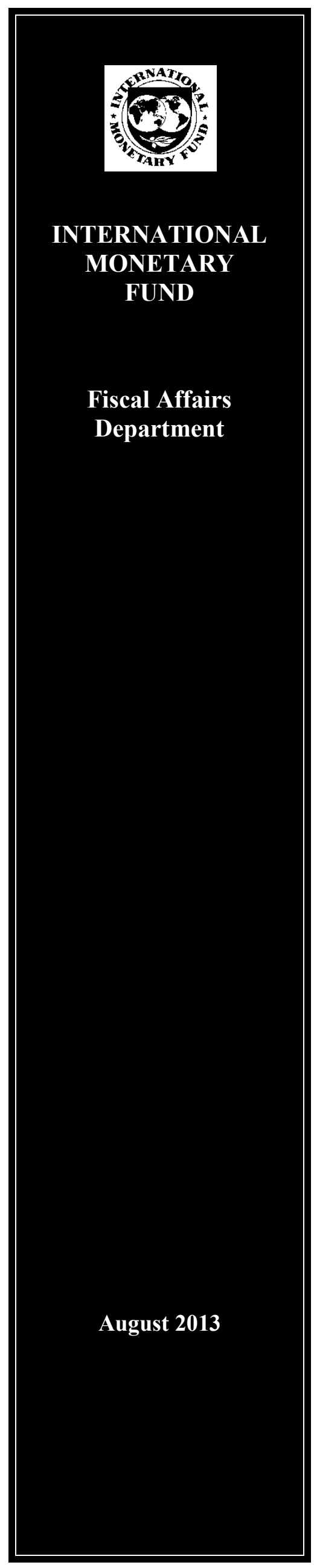

Continued Modernization of the Malian Tax System and Administration

Patrick Fossat, Gilles Montagnat-Rentier, Patrick Petit, Gilles Parent, Gerard Chambas, and Johanne Russell 


\section{INTERNATIONAL MONETARY FUND}

Fiscal Affairs Department

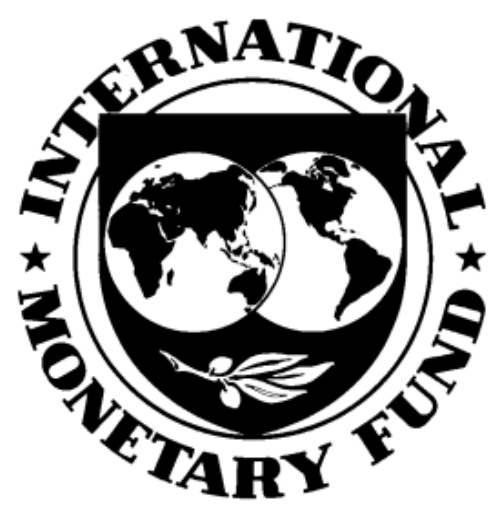

MALI

Continued Modernization of The Malian TAX System AND ADMINISTRATION

Patrick Fossat, Gilles Montagnat-Rentier, Patrick Petit, Gilles Parent, Gérard Chambas, and Johanne Russell

August 2013 
Preface

Abbreviations and Acronyms .................................................................................... vii

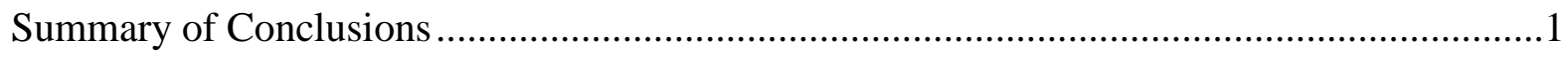

I. Results of Reforms of Tax System and Administration ......................................................

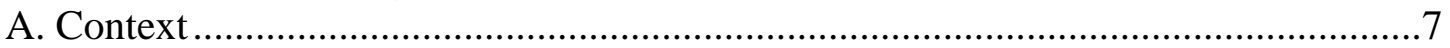

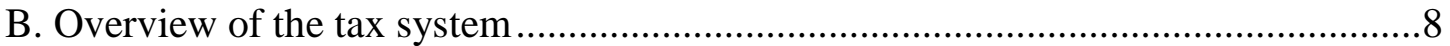

C. Position of the tax administration...................................................................... 10

D. Position of the customs administration ...............................................................11

E. Key challenges faced ...................................................................................... 12

F. Objectives for continued reforms ......................................................................13

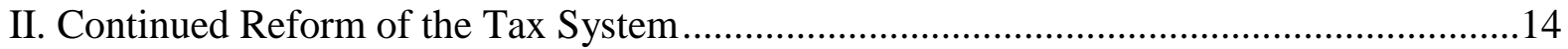

A. Taxation of corporate and individual incomes....................................................14

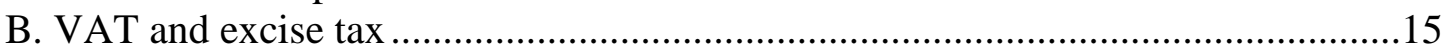

C. Stamp tax, recording fees, business tax, and other minor taxes...............................16

III. Priority Measures to Strengthening Tax Administration ..................................................19

A. Control of tax obligations …………………..................................................19

B. Measures to improve the effectiveness of tax audits.............................................20

C. Measures to improve the research activity and expand the tax base........................23

D. Framework for elimination of VAT withholding ...............................................26

E. Other measures to improve offices' efficiency …………………………………....28

IV. Priority Measures to Strengthen Customs administration .................................................31

A. Control of commercial operations.....................................................................31

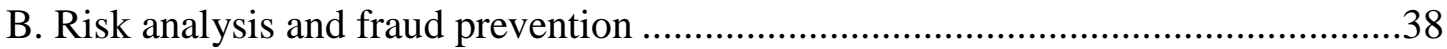

C. Trade facilitation and partnership .......................................................................4

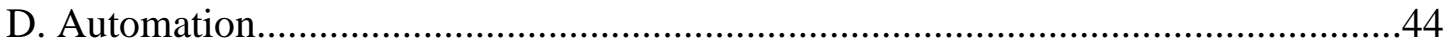

E. Resource management and supervision of services ………………………….......46

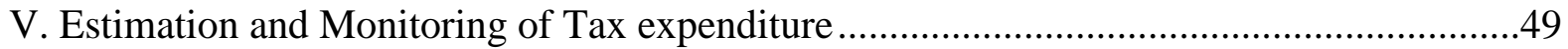

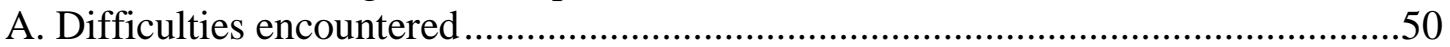


Tables

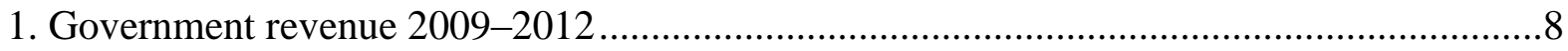

2. Implementation of Recommendations of the 2010 FAD Mission ................................... 9

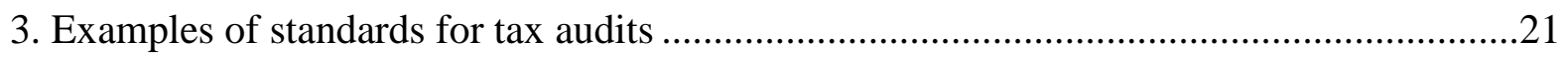

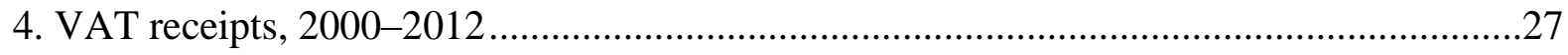

5. Sample classification of outstanding taxes to determine "recoverability"........................29

6. Customs disputes by type of violation, January-May 2013 (en CFAF) ............................33

7. Proposed reorganization of customs control of commercial operations .............................34

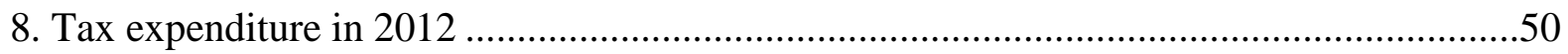

Figures

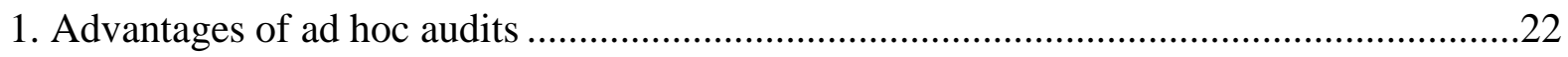

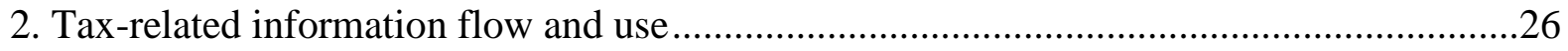

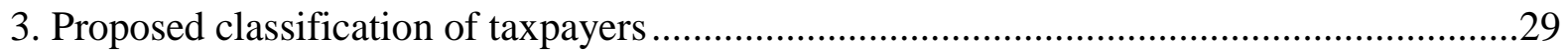

Annexes

1. Implementation Status of Recommendations of the 2011 FAD Mission ..........................55

2. Implementation Status of Recommendations of the ................................................57

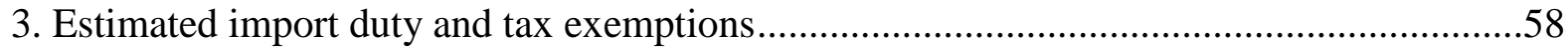

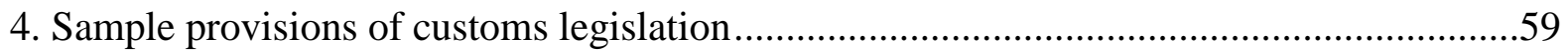




\section{Abbreviations and Acronyms}

\begin{tabular}{|l|l|}
\hline ADIT & Estimated payment of multiple taxes \\
\hline AFRITAC West & Africa Regional Technical Assistance Center West \\
\hline ASYCUDA & Automated Customs Management System \\
\hline BCEAO & Central Bank of West African States \\
\hline BCT & Transit control bureau \\
\hline CDI & Individual taxpayer office (centre des impôts) \\
\hline CFAF & CFA Franc \\
\hline CNPM & Malian National Employers Council \\
\hline DAV & Directorate of Verification Support \\
\hline DCAD & Directorate of Post-clearance Inspections \\
\hline DFPE & Directorate of Enterprises Facilitation and Partnership \\
\hline DGD & Directorate General of Customs \\
\hline DGE & Directorate General Large Business Taxpayers \\
\hline DGI & Directorate General of Taxation \\
\hline DID & Directorate General of District Taxes \\
\hline DME & Directorate of Medium-Sized Business Taxpayers \\
\hline DNDC & Directorate General of Government Lands and the Cadaster \\
\hline DNTCP & Directorate General of the Treasury and Public Accounting \\
\hline DRE & Research and Investigation Division \\
\hline DRED & Directorate of Customs Intelligence and Investigations \\
\hline DRI & Regional tax directorate \\
\hline Ébémi & Electronic vehicle position monitoring system \\
\hline FAD & IMF Fiscal Affairs Department \\
\hline GATT & General Agreement on Trade and Tariffs \\
\hline GPRS & Growth and Poverty Reduction Strategy \\
\hline IBIC & Tax on industrial and commercial profits \\
\hline IMF & International Monetary Fund \\
\hline IRVM & Tax on income from securities \\
\hline IS & Corporate tax \\
\hline ITS & Personal income tax \\
\hline MDG & Millennium Development Goals \\
\hline MNRW-TTF & Managing Natural Resources Wealth - Topical Trust Fund \\
\hline NIF & Taxpayer identification number \\
\hline OEA & Accredited economic operator \\
\hline OHADA & Organization for the Harmonization of Business Law in Africa \\
\hline PAGAM-GFP & $\begin{array}{l}\text { Government Action Plan to Improve and Modernize Public Financial } \\
\text { Management }\end{array}$ \\
\hline PAMORI & Project to Support Domestic Revenue Collection \\
\hline & \\
\hline
\end{tabular}




\begin{tabular}{|l|l|}
\hline PEDONIA & Customs personnel database \\
\hline PRED & Plan for the Sustainable Recovery of Mali \\
\hline RNI & Standard tax system \\
\hline RSI & Simplified tax system \\
\hline SDRAV & Subdirectorate of Research and Verification Support \\
\hline SIGTAS & Automated Tax Management System \\
\hline SRFP & Public Finance Strengthening Strategy \\
\hline TPA-TTF & Tax Policy and Administration - Topical Trust Fund \\
\hline UNCTAD & United Nations Conference on Trade and Development \\
\hline VAT & Value added tax \\
\hline WAEMU & West African Economic and Monetary Union \\
\hline WCO & World Customs Organization \\
\hline
\end{tabular}




\section{PrefaCe}

At the request of the Malian authorities, the IMF Fiscal Affairs Department (FAD) arranged for technical assistance missions in tax policy and tax and customs administration in Bamako during June 10-21 (tax policy) and June 17-28, 2013 (tax and customs administration). The mission team consisted of Messrs. Patrick Fossat, Patrick Petit, Gilles Montagnat-Rentier and Gilles Parent (FAD); Mr. Gérard Chambas (expert); and Ms. Johanne Russell, resident advisor in customs administration with the IMF Africa Regional Technical Assistance Center West (West AFRITAC).

The purpose of the mission was to evaluate the reforms implemented to modernize the tax system administration and make recommendations to strengthen tax legislation and improve the operations of the tax and customs administrations.

The mission was introduced to Mr. Tiéna Coulibaly, Minister of the Economy, Finance, and Budget. ${ }^{1}$ The mission conclusions were presented to Mr. Abdel Karim Konaté, Minister of Finance and Mr. Manadou Namory Traore, Minister of the Economy and Humanitarian Action. The team met extensively with Mr. Dionké Diarra, Director General of Taxation; Mr. Moumouni Dembele, Director General of Customs, and their key associates in the headquarters and Bamako offices*; Mr. Konzo Traoré, BCEAO National Director; Mr. Lamine Alexis Dembele, Director General, Oil Exploration Promotion Authority; Mr. Lanssana Guindo, Director General, National Directorate of Geology and Mines; Mr. Harouna Koné, Deputy Director General, National Statistics Institute; Mr. Rantobeng William Mokou, Ambassador of South Africa; Mr. Boubacar K. Coulibaly, Director General, Directorate General of State Property Administration; and Dr. Bréhima Kamena, Secretary-General, Ministry of Mines.

A meeting was arranged with representatives of the Malian National Employers Council (CNPM) and economic operators. The mission also held a meeting with representatives of the French Development Agency; the African Development Bank; the German, Danish, and French development cooperation agencies; and the United Nations Development Program. The mission also had contacts with a joint delegation from the French foreign ministry and customs administration visiting the Directorate General of Customs (DGD) and the pre-shipment inspection company BIVAC.

\footnotetext{
${ }^{1}$ A new minister of finance took office during the mission.

* [Tr.: the authors use the word "services" to refer to disparate divisional entities. Except where "services" means "staff," "services" is translated herein as "offices."]
} 
The mission's work was facilitated by the IMF resident representative in Bamako; Mr. Mamadou Berté, head of the reforms support unit for the Directorate General of Taxation (DGI); and Col. Baba Kida, Director of Revenue, Planning, and Inspection Programs for the DGD.

The mission would like to thank all the individuals with whom it met for their hospitality and cooperation with the team.

This report presents a summary of the conclusions and five chapters: (I) results of reforms in the tax system and administration; (II) continued reform of the tax system; (III) priority measures to improve tax administration; (IV) priority measures to improve customs administration; and (V) estimation and monitoring of tax expenditure. 


\section{SUMMARY OF CONCLUSIONS}

The crisis that has afflicted Mali since 2012 has had an adverse economic impact, reflected in a 25 percent decline in government resources and negative growth of -1.2 percent. Despite the difficult context, the combination of reduced investment expenditure, improved tax collection, reduced subsidies, and increased taxes on petroleum products served to contain the budget deficit at 1.3 percent of GDP.

In regard to increasing own resources, the government is committed to increasing tax receipts to reduce dependence on foreign aid. From that perspective, the mission proposes measures to improve the tax system and strengthen tax and customs administration capacities (see mission recommendations presented in the table below).

\section{Tax policy}

Since the September 2010 FAD mission, several tax policy measures have been implemented, including the reduction of certain rates (corporate tax (IS) and tax on industrial and commercial profits (IBIC) from 35 percent to 30 percent, property tax from 15 percent to 8 percent, capital gains tax from 35 percent to 25 percent), an increase in the alternative minimum flat tax from 0.75 percent to 1 percent, the introduction of a 2 percent tax on the cost of telecommunications, and elimination of estimated payments of multiple taxes (ADIT) (except for unregistered businesses).

Regarding VAT in particular, withholding at source was gradually eliminated in June 2012 except on transactions with the Treasury, which still withholds 40 percent of the VAT; and the system for refunding VAT credits was improved (escrow account opened at the BCEAO, extension of right to refund to all noncommercial businesses).

In regard to tax expenditure, the initial estimate presents a number of weaknesses to be corrected, including a poorly defined reference tax system, an insufficient inventory of exemptions and exceptional measures, and estimation methods relying exclusively on unadjusted tax or customs statistics.

\section{Tax administration}

The crisis primarily affected the operations of offices located in the North, whose contribution to domestic tax revenue is less than 1 percent. The impact of the crisis on the activities of economic operators was not estimated (however, 52 medium-size businesses report that they have discontinued operations). With the exception of the northern regions whose personnel were redeployed in other regions, activities were not interrupted and implementation of the reforms continued. Significant measures have been carried out since the 2011 FAD mission, including elimination of VAT withholding, revision of the VAT threshold (which will be increased to 
CFAF 100 million in 2014), modification of the business turnover thresholds used to delimit the operational offices' responsibilities, a study of a simplified tax system for small businesses, and an initial estimate of tax expenditure.

The continued strengthening of tax administration capacities faces a number of challenges, including: (1) effective monitoring of tax obligations: over 25 percent of medium-sized businesses and over 70 percent of the small businesses identified do not comply with their tax obligations, and only one in five businesses pays net VAT; (2) expansion of the tax base: the DGI identified only 1,600 firms generating sales above CFAF 100 million; (3) reduction and control of outstanding tax liabilities, which have quadrupled since 2012; and (4) promotion of voluntary tax compliance, in particular through improved quality of the services delivered to taxpayers, simplified and modernized procedures, and professionalization of tax administration personnel.

\section{Customs administration}

In a critical context following the looting of customs offices in March 2012 and reduced imports, the DGD took immediate measures to ensure continued operations and the collection of duties and taxes. Ultimately, customs receipts were only moderately affected by the situation. The director general reestablished the steering committee and resumed important reforms, which resulted in the adoption of a new organizational chart and several official texts establishing the offices' missions and functions, the framework for personnel management, and rules of professional conduct.

The 2011-2015 strategic plan is relevant and has already produced significant progress, particularly in the areas of training, internal control, securing of goods in transit from ports, and the establishment of fraud prevention units. The mission observed sound customs administration operations.

To continue the modernization efforts begun, the following objectives are proposed:

$\checkmark \quad$ Introduce the model organization of commercial operations control used by more advanced customs services, which is based on risk management, segmentation of operators, targeted inspections during clearance, and the preponderance of heightened post-clearance inspections. This model is needed to significantly increase receipts and overcome the limits necessarily imposed by traditional controls in customs bureaus.

$\checkmark$ Strengthen capacities to control commercial customs fraud and cross-border crime by promoting the creation of databases, collection of information, and use of information by specialized mobile units working in cooperation with other such units. The DGD should acquire strong capacities in technical areas (value, origin, tariff description). 
$\checkmark$ Develop the trade facilitation mission and partnership with operators to enable the DGD to fulfill its role in improving the business environment.

$\checkmark$ Use the migration to the World version of ASYCUDA as an opportunity to optimize processes, secure procedures, and prepare for paperless processing.

$\checkmark$ Modernize personnel management and the delineation of offices' functions and responsibilities: the DGD should estimate personnel requirements, implement forward management, rationalize functional and geographic deployment of staff, and continue the training and internal control programs being implemented.

\section{Continued technical assistance}

The authorities presented a request for technical assistance in connection with programs supported by several development partners. Subject to available financing capacity, the mission believes the Malian authorities and administrations concerned meet the conditions to receive technical assistance in the context of: (1) the Tax Policy and Administration Topical Trust Fund (TPA-TTF); and (2) the Managing Natural Resources Wealth Topical Trust Fund (MNRWTTF).

\section{Matrix of recommendations for continued reform of the tax system and strengthening of the tax and customs administrations}

\begin{tabular}{|c|c|}
\hline Recommendations & Deadline \\
\hline \multicolumn{2}{|l|}{ I. $\quad$ Tax policy reform } \\
\hline $\begin{array}{l}\text { Prepare an action plan detailing the context of the tax policy reform, } \\
\text { the rationale and objectives for the reforms, the measures } \\
\text { contemplated, and the timetable for implementation. }\end{array}$ & September 2013 \\
\hline $\begin{array}{l}\text { - Extend the length of time a deficit may be carried over to at least five } \\
\text { years. }\end{array}$ & 2014 budget law \\
\hline - Limit the amount of interest expense deducted from earnings & 2014 budget law \\
\hline $\begin{array}{l}\text { - Align the tax treatment of investment companies with general tax } \\
\text { provisions. }\end{array}$ & 2015 \\
\hline - Eliminate the reduced VAT rate and do not replace it with exemptions. & 2015 \\
\hline $\begin{array}{l}\text { - Harmonize the VAT threshold with the threshold for medium-sized } \\
\text { businesses. }\end{array}$ & January 2014 \\
\hline $\begin{array}{l}\text { Do not impose VAT on stock companies (legal entities) with turnover } \\
\text { below the VAT threshold; apply the alternative business income tax } \\
\text { instead, and give them the option of choosing to pay VAT. }\end{array}$ & $\begin{array}{l}\text { Upon introduction } \\
\text { of the alternative } \\
\text { tax }\end{array}$ \\
\hline $\begin{array}{l}\text { Accelerate refunds of VAT credits by deduction from DGI gross } \\
\text { receipts (with minimum control by the Treasury). }\end{array}$ & End-2013 \\
\hline - Impose VAT on businesses governed by sector codes. & 2015 \\
\hline - Revise excise tax rates in accordance with the 2010 FAD report. & 2014 \\
\hline $\begin{array}{l}\text { - Establish a government position on issues of recording fees, stamp } \\
\text { taxes and business income taxes and include this position in the action } \\
\text { plan. }\end{array}$ & End-2013 \\
\hline
\end{tabular}




\begin{tabular}{|c|c|}
\hline \multicolumn{2}{|l|}{ II. $\quad$ Strengthening tax administration } \\
\hline VAT administration & \\
\hline $\begin{array}{l}\text { - Improve monitoring of tax obligations with a view toward reducing the } \\
\text { nonfiler rate below } 10 \text { percent for the Directorate of Medium-Sized } \\
\text { Business Taxpayers (DME) and } 15 \text { percent for the individual taxpayer } \\
\text { offices (centres des impôts, CDI). }\end{array}$ & December 2014 \\
\hline - Launch a campaign to promote control of VAT credits. & Immediate \\
\hline - Apply the VAT threshold to legal entities. & 2015 budget law \\
\hline - Simplify the so-called simplified tax system (RSI) & 2015 budget law \\
\hline - Modernize payment procedures. & 2014 \\
\hline \multicolumn{2}{|l|}{ Tax audits } \\
\hline - Revise the tax inspectors' objectives. & End-2103 \\
\hline $\begin{array}{l}\text { - Give preference to ad hoc audit procedures to verify situations of non- } \\
\text { payment and VAT credits. }\end{array}$ & Immediate \\
\hline - Organize tax inspectors into teams headed by a leader & End-2013 \\
\hline $\begin{array}{l}\text { - Refocus quality control of inspections so as to emphasize the analysis } \\
\text { of results. }\end{array}$ & End-2013 \\
\hline \multicolumn{2}{|l|}{ Expansion of tax base } \\
\hline $\begin{array}{l}\text { - Clarify the respective roles of the joint interagency committee and the } \\
\text { DGI research office to avoid overlapping areas of authority. }\end{array}$ & Immediate \\
\hline - Define a clear strategy for the collection and use of tax information. & August 2013 \\
\hline - Provide access to tax records and taxpayer rolls for the research team & Immediate \\
\hline \multicolumn{2}{|l|}{ Elimination of VAT withholding at source } \\
\hline $\begin{array}{l}\text { - In conducting ad hoc audits, give priority to the largest suppliers of } 50 \\
\text { large businesses now exempt from withholding. }\end{array}$ & Starting July 2013 \\
\hline $\begin{array}{l}\text { - Conduct a targeted communication action regarding VAT reporting } \\
\text { obligations, particularly among suppliers to large businesses and all } \\
\text { government suppliers. }\end{array}$ & $\begin{array}{l}\text { Prior to September } \\
2013\end{array}$ \\
\hline $\begin{array}{l}\text { Provide for more responsive control of effective VAT payment by } \\
\text { government suppliers after the VAT deduction for public contracts is } \\
\text { eliminated in early } 2014 \text {. }\end{array}$ & $\begin{array}{l}\text { Starting February } \\
\qquad 2014\end{array}$ \\
\hline \multicolumn{2}{|l|}{ Outstanding payments management } \\
\hline $\begin{array}{l}\text { Establish a strategy for clearing tax arrears based on the classification } \\
\text { by type, age, and amount to determine the recoverability rate. }\end{array}$ & September 2013 \\
\hline
\end{tabular}




\begin{tabular}{|c|c|}
\hline \multicolumn{2}{|l|}{ III. $\quad$ Strengthening customs administration $^{2}$} \\
\hline Control of commercial operations & \\
\hline $\begin{array}{l}\text { - Extend the secure transit mechanism (regional T1, Ébémi, and mobile } \\
\text { brigades) to all corridors; rigorously collect duties payable (see } \\
\text { recommended measures). }\end{array}$ & $\begin{array}{l}2015 \text { (corridors) } \\
\text { September } 2013 \\
\quad \text { (duties) }\end{array}$ \\
\hline $\begin{array}{l}\text { Implement the new organization of inspections proposed between the } \\
\text { first and second lines. }\end{array}$ & January 2014 \\
\hline $\begin{array}{l}\text { Have the Value, Origin and Tariff Division specialize in research and } \\
\text { analysis to support the customs bureaus and operational directorates; } \\
\text { gradually redefine the inspection company services as capacities are } \\
\text { acquired by the division. }\end{array}$ & Mid-2014 \\
\hline $\begin{array}{l}\text { Verify WAEMU certificates of origin more systematically in } \\
\text { cooperation with the issuing authority and take the actions } \\
\text { authorized. }\end{array}$ & $\begin{array}{c}\text { January 2014- } \\
\text { Ongoing }\end{array}$ \\
\hline $\begin{array}{l}\text { Continue to professionalize the Directorate of Post-clearance } \\
\text { Inspections. }\end{array}$ & Ongoing \\
\hline $\begin{array}{l}\text { - Create a unit to enforce collection of custom debts arising other than } \\
\text { from clearance, and propose adaptations of legal powers if necessary. }\end{array}$ & January 2014 \\
\hline $\begin{array}{l}\text { - Closely monitor changes in volumes of petroleum products released } \\
\text { to the market. }\end{array}$ & Ongoing \\
\hline $\begin{array}{l}\text { - Obtain the gold ore refining report for potential correction of } \\
\text { declared values. }\end{array}$ & January 2014 \\
\hline \multicolumn{2}{|l|}{ Risk analysis and fraud prevention } \\
\hline $\begin{array}{l}\text { - Restart the automated risk analysis project, beginning with } \\
\text { automation of the CX file. }\end{array}$ & $\begin{array}{l}\text { Oct.-Nov. } 2013 \\
\text { (AFRITAC visit) }\end{array}$ \\
\hline $\begin{array}{l}\text { - Conduct the investigations, analyses, and studies required to improve } \\
\text { the automated risk analysis database (first line) and provided input to } \\
\text { the national fraud database (for the other offices). }\end{array}$ & Ongoing \\
\hline $\begin{array}{l}\text { - Incorporate suspected irregularities detected by the scanner into the } \\
\text { ASYCUDA warnings. }\end{array}$ & September 2014 \\
\hline $\begin{array}{l}\text { - Coordinate fraud prevention efforts under a national plan, the } \\
\text { application of a control and investigation rating, and a coordination } \\
\text { center for interventions on the ground. }\end{array}$ & $\begin{array}{l}\text { January } 2014 \text { (plan, } \\
\text { rating) } \\
\text { June } 2014 \text { (center) }\end{array}$ \\
\hline $\begin{array}{l}\text { - Consider simplification of the organizational structure of the } \\
\text { Directorate of Customs Intelligence and Investigations and avoid } \\
\text { duplication of deferred inspections by the bureaus. }\end{array}$ & January 2014 \\
\hline
\end{tabular}

\footnotetext{
${ }^{2}$ The recommendations regarding the customs administration were detailed to facilitate update of the existing strategic action plan.
} 


\begin{tabular}{|c|c|}
\hline \multicolumn{2}{|l|}{ Trade facilitation and partnership } \\
\hline $\begin{array}{l}\text { Establish a framework for consultation with operators to discuss the } \\
\text { proposed reforms (first level) and resolve practical problems (second } \\
\text { level). }\end{array}$ & September 2013 \\
\hline $\begin{array}{l}\text { - Develop an action plan for the Directorate of Facilitation and } \\
\text { Partnership with Business, including, inter alia: } \\
\circ \quad \text { the recommended procedural simplifications (elimination of } \\
\text { the manifest, sealed containers cleared at domicile, } \\
\text { automation of D24); } \\
\circ \text { gradual reduction of clearance times; } \\
\circ \text { adaptation if necessary and promotion of economic systems; } \\
\circ \quad \text { a pilot preferred operators program; } \\
\circ \quad \text { framework and the extension of rights of appeal; } \\
\circ \quad \text { individual assistance to operators. }\end{array}$ & January 2014 \\
\hline \multicolumn{2}{|l|}{ Automation } \\
\hline $\begin{array}{l}\text { - Continue the project supported by the French authorities to install } \\
\text { data centers. }\end{array}$ & End-2013 \\
\hline $\begin{array}{l}\text { Take the opportunity to rationalize and simplify procedures in } \\
\text { connection with the migration to ASYCUDA World and develop } \\
\text { functionalities likely to bring about improvements in the short term. }\end{array}$ & 2 January 2015 \\
\hline $\begin{array}{l}\text { In the medium term, begin a project to automate the documents } \\
\text { required for customs clearance and implement a one-stop } \\
\text { international trade window. }\end{array}$ & Early 2015 \\
\hline - Recruit and train a sufficient number of IT staff. & Immediate \\
\hline \multicolumn{2}{|l|}{ Resource management and delineation of offices' functions } \\
\hline $\begin{array}{l}\text { Once the personnel file is recreated, adopt a forward approach to } \\
\text { personnel management, including programming of training and } \\
\text { recruiting. }\end{array}$ & January 2014 \\
\hline $\begin{array}{l}\text { - Negotiate a ministerial agreement with Ministry of the Civil Service } \\
\text { whereby the DGD determines its specific hiring needs in terms of } \\
\text { both category and specialization. }\end{array}$ & End-2013 \\
\hline $\begin{array}{l}\text { - Launch a national geographic and functional redeployment plan, and } \\
\text { limit the rotation of specialized personnel to optimize the training } \\
\text { provided. }\end{array}$ & January 2014 \\
\hline $\begin{array}{l}\text { Implement a performance contract and use it as a tool for continued } \\
\text { improvement in carrying out all functions rather than limiting it to } \\
\text { collection results. }\end{array}$ & January 2014 \\
\hline $\begin{array}{l}\text { - Continue strengthening internal controls according to the principles } \\
\text { established, following through with proposed remedial measures and } \\
\text { sanctions, and including control of use of the information system and } \\
\text { data. }\end{array}$ & $\begin{array}{c}\text { Ongoing } \\
2014 \text { (automation) }\end{array}$ \\
\hline $\begin{array}{l}\text { - Implement a program to ensure all personnel are fully aware of the } \\
\text { obligations provided by the code of ethics. }\end{array}$ & January 2014 - Ongoing \\
\hline
\end{tabular}




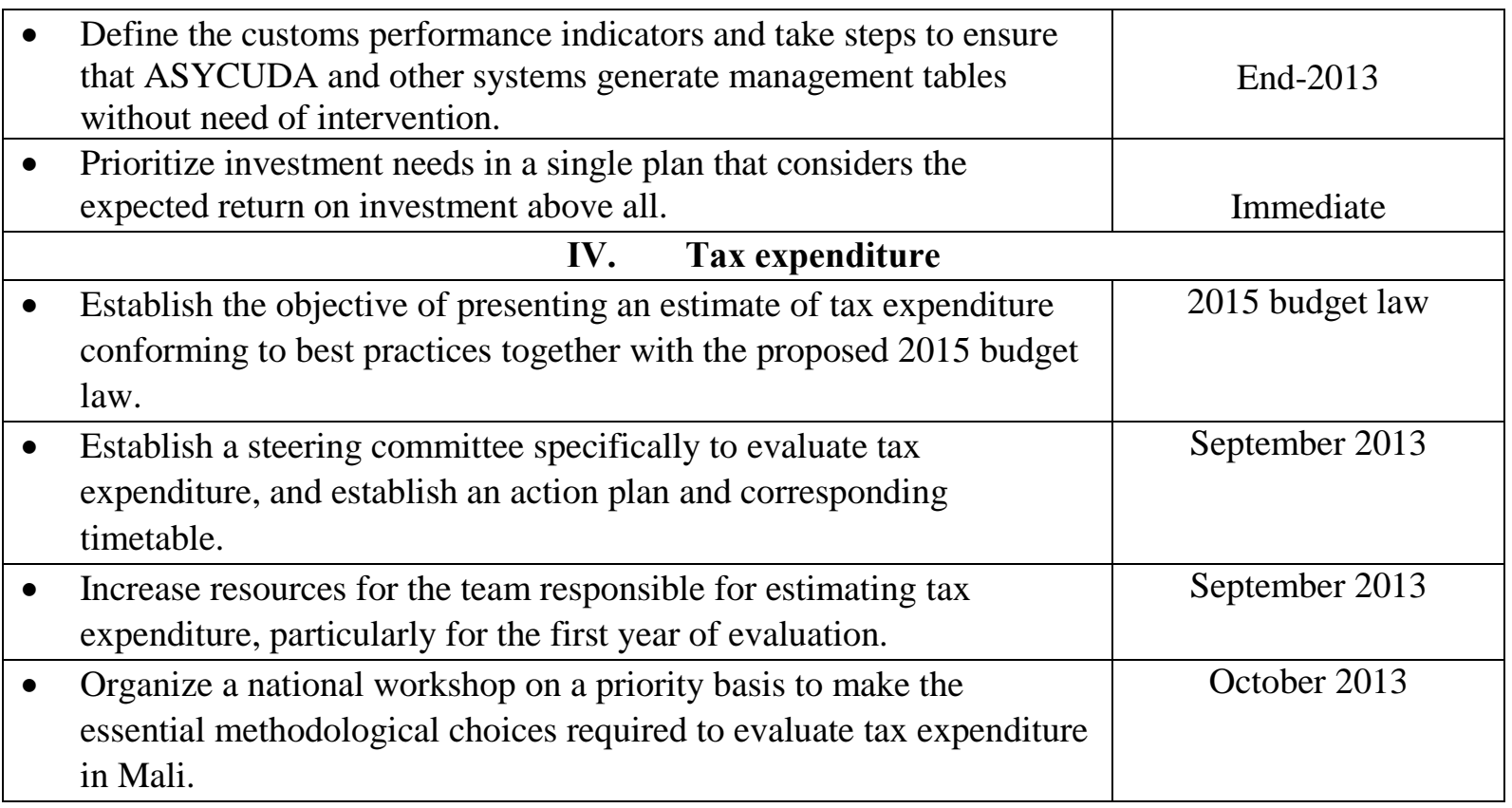

\section{RESULTS OF REFORMS OF TAX SYSTEM AND ADMINISTRATION}

\section{A. Context}

1. Mali experienced a serious crisis in 2012 and 2013 following the occupation of Northern Mali by armed groups beginning in January 2012 and the coup d'état of March 22, 2012. From an economic standpoint, the crisis had a negative impact affecting primarily: (1) public development assistance (other than emergency aid and aid to the population) resulting in a 30 percent reduction in government resources; and (2) economic activity, resulting in negative growth of -1.2 percent compared to a positive rate of 4.3 percent in 2011 . As a result, the poverty rate increased from 41.7 percent in 2011 to 42.7 percent in 2012.

2. However, despite the difficult context, the combination of reduced investment spending, improved tax collection, reduced subsidies, and increased taxation of petroleum products contained the budget deficit at 1.3 percent of GDP. Table 1 presents government receipts for the period 2009-2013 (as at May 31).

3. After a transition government was formed, a Plan for the Sustainable Recovery of Mali (PRED) for the period 2013-2014 was prepared in April 2013 by the international conference "Ensemble pour le Renouveau du Mali" (Ensemble for the Renewal of Mali). The main objectives of the PRED are to develop infrastructure throughout the country and improve daily living conditions for Malian citizens. The financing requirements, CFAF 2,849 billion, reflect the ambitions of the project, and will be provided from Mali's own resources and international aid.

4. With respect to increasing own resources, the government is committed to improving revenue collection to reduce dependence on international aid. In this context, the present mission 
proposes solutions for tax legislation better adapted to the objectives sought and measures to strengthen the tax and customs administrations' tax-collecting capacities.

5. Particular attention will be focused on the extractive sector, which was addressed in a separate analysis - cf. memorandum entitled "Mali - Natural Resource Management," which the mission presented to the authorities and is attached to this report. With 26 tons of gold exported in 2012, the sector represents 20 percent of government receipts and 70 percent of exports, making Mali is the third largest African producer. However, weak management of the tax base, the presence of stabilized operation agreements, and the closing of several mines in the short and medium term pose significant challenges to raising taxes from the sector. The dependence vis-à-vis the gold sector will also be reduced if Mali takes full advantage, in the long term, of its promising subsoil resources, the potential of which is largely unknown. In fact, development of the extractive sector could contribute to reducing poverty over the long term.

Table 1. Government revenue 2009-2012

(CFAF millions)

\begin{tabular}{|c|c|c|c|c|}
\hline & 2009 & 2010 & 2011 & 2012 \\
\hline Total receipts & $5,88,135$ & 653,465 & 728,330 & 767,652 \\
\hline Direct taxes & 167,763 & 204,565 & 220,836 & 263,222 \\
\hline $\begin{array}{l}\text { Tax on industrial and commercial } \\
\text { profits (IBIC) }\end{array}$ & 5,442 & 2,021 & 3,272 & 2,539 \\
\hline Corporate tax & 85,330 & 107,705 & 100,367 & 116,058 \\
\hline Alternative min. business tax & 1,117 & 1,198 & 1,328 & 1,224 \\
\hline Income tax & 41,013 & 54,673 & 65,452 & 77,776 \\
\hline Other taxes, assessments, fees & 34,861 & 38,968 & 50,417 & 65,625 \\
\hline Indirect taxes & 292,818 & 310,960 & 372,416 & 362,776 \\
\hline VAT & 248,369 & 261,873 & 310,488 & 286,504 \\
\hline Of which VAT on imports & 153,875 & 162,945 & 185,505 & 171,501 \\
\hline domestic VAT & 94,494 & 98,928 & 115,033 & 103,224 \\
\hline BCEAO VAT account & l & l & 9,950 & 11,779 \\
\hline Taxes on beverages & $, 2,606$ & 3,151 & 3,812 & 4,731 \\
\hline Tax on financial activities & 14,184 & 17,836 & 18,799 & 22,852 \\
\hline Services tax (CPS) on gold & 18,434 & 20,503 & 23,694 & 33,827 \\
\hline Other indirect taxes & 9,225 & 7,599 & 15,623 & 14,862 \\
\hline Recording fees, stamp tax, other taxes & 14,395 & 17,757 & 18,416 & 15,859 \\
\hline Taxes on foreign trade & 113,159 & 120,183 & 116,662 & 125,795 \\
\hline Customs duties & 73,344 & 77,822 & 91,594 & 80,983 \\
\hline $\begin{array}{l}\text { WAEMU tariff (Redevance } \\
\text { Statistique) }\end{array}$ & 7,752 & 8,583 & 10,418 & 9,695 \\
\hline Other taxes collected by Customs & 32,063 & 33,778 & 14,650 & 35,117 \\
\hline GDP (CFAF billion) & 4,233 & 4,656 & 5,028 & 5,243 \\
\hline Total receipts /GDP & $14.7 \%$ & $14.8 \%$ & $14.5 \%$ & 14.8 \\
\hline VAT / GDP & $5.8 \%$ & $5.6 \%$ & $6.2 \%$ & $5.5 \%$ \\
\hline
\end{tabular}

\section{B. Overview of the tax system}

6. Mali's tax system was addressed in a diagnostic assessment by a September 2010 FAD mission (see Table 2 on the implementation of the mission's recommendations). 
Table 2. Implementation of Recommendations of the 2010 FAD Mission

\begin{tabular}{|c|c|}
\hline Recommendation & Action taken \\
\hline $\begin{array}{l}\text { Tighten the eligibility criteria provided in the Investment Code, simplify } \\
\text { licensing procedures, eliminate sector codes (except the mining and } \\
\text { petroleum codes), impose VAT on suppliers, and account for tax expenditure } \\
\text { annually. }\end{array}$ & $\begin{array}{l}\text { No action in this area other than to begin a study on } \\
\text { tax expenditure (cf. section V). }\end{array}$ \\
\hline $\begin{array}{l}\text { Increase the VAT threshold, clear non-refunded credits and improve the } \\
\text { refund procedure, eliminate VAT withholding, impose VAT on petroleum } \\
\text { products and banks, maintain the single rate, and reduce exemptions. }\end{array}$ & $\begin{array}{l}\text { The VAT threshold was increased from CFAF } 30 \text { to } \\
50 \text { million. It will be raised to CFAF } 100 \text { million in } \\
2014 \text {. Withholding was eliminated except for public } \\
\text { contracts (for which it was reduced to } 40 \text { percent, } \\
\text { however). It will be completely eliminated as at } \\
\text { January } 1,2014 \text {. The reduced VAT rate was } \\
\text { maintained. }\end{array}$ \\
\hline $\begin{array}{l}\text { Evaluate the inventory of VAT credits in the very short term, discontinue the } \\
\text { practice of refunding VAT credits through contracts, and establish the } \\
\text { administrative framework to manage the recent extension of the right to } \\
\text { refund [to] generally applicable laws. }\end{array}$ & $\begin{array}{l}\text { The inventory of aged credits (CFAF } 35 \text { billion) was } \\
\text { cleared and the refund procedure was improved: } \\
\text { account was opened at the BCEAO to which a portion } \\
\text { of gross VAT is deposited, and extension of refund to } \\
\text { all activities (except purchase-resale). }\end{array}$ \\
\hline $\begin{array}{l}\text { Increase excise taxes on tobacco and alcohol and apply excise taxes to a base } \\
\text { defined by regional Directors, introduce an excise tax on high-end tourist } \\
\text { vehicles, review the role of excise tax on petroleum products, and introduce a } \\
\text { direct, transparent subsidy mechanism to replace the variable excise tax. }\end{array}$ & $\begin{array}{l}\text { Legislation on excise taxes was aligned with the } \\
\text { WAEMU directive without changing the rates. }\end{array}$ \\
\hline $\begin{array}{l}\text { Lower the corporate tax (IS) rate for the mining sector and the IBIC rate to } 35 \\
\text { percent and increase the alternative minimum business tax (impot } \\
\text { synthétique) from } 0.75 \text { percent to } 1 \text { percent; tax the agriculture sector, } \\
\text { increase loss carryovers to five years, include all business income (including } \\
\text { capital gains) in the taxable base for the IS and IBIC, limit the deductibility of } \\
\text { interest expense, tax investment companies, and introduce an alternate tax } \\
\text { proportional to turnover for tax payers below the VAT threshold. }\end{array}$ & $\begin{array}{l}\text { The IS and IBIC rates were lowered from } 35 \text { percent } \\
\text { to } 30 \text { percent and the alternative minimum business } \\
\text { tax was increased to } 1 \text { percent. Income from property } \\
\text { and income from securities (IRVM) are included in } \\
\text { the taxable base for purposes of IS. }\end{array}$ \\
\hline $\begin{array}{l}\text { Harmonize the tax in income from securities (IRVM) with WAEMU } \\
\text { directives. }\end{array}$ & Completed. \\
\hline $\begin{array}{l}\text { Conduct simulations to reduce the number of tax brackets for personal } \\
\text { income tax (ITS), cap the maximum rate at } 35 \text { percent, and tax property } \\
\text { income for individuals at } 10 \text { percent. }\end{array}$ & $\begin{array}{l}\text { The property income tax (IRF) was reduced from } 15 \\
\text { percent to } 10 \text { percent for buildings of permanent and } \\
\text { semi-permanent materials, and from } 10 \text { percent to } 8 \\
\text { percent for mud buildings. }\end{array}$ \\
\hline $\begin{array}{l}\text { Consider the ADIT as an estimated payment of income tax (IS or IBIC); } \\
\text { eventually eliminate the } 3 \text { percent rate and reduce the rate for importers } \\
\text { without a taxpayer identification number to } 5 \text { percent. }\end{array}$ & $\begin{array}{l}\text { The ADIT has been limited to transactions with the } \\
\text { Treasury and taxpayers without a taxpayer } \\
\text { identification number. }\end{array}$ \\
\hline $\begin{array}{l}\text { For individuals, establish a rate of } 10 \text { percent on dividends and capital gains } \\
\text { on the sale of real and movable property. Reserve a reduced rate of } 7 \text { percent } \\
\text { in accordance with the regional directive. }\end{array}$ & $\begin{array}{l}\text { The capital gains tax for transactions and movable } \\
\text { and real property was reduced from } 35 \text { percent to } 25 \\
\text { percent for natural persons (if held less than two } \\
\text { years) and from } 15 \text { percent to } 10 \text { percent (if held more } \\
\text { than two years). }\end{array}$ \\
\hline
\end{tabular}

7. The reforms identified by the 2010 FAD mission that have not yet been adopted are expected to form the core of Mali's next tax reform. The reform effort in the coming years will address:

$\checkmark$ Reform of the system of tax exemptions and other investment incentives in order to improve the business environment. 
$\checkmark$ Adjustments of the corporate tax rate and taxable base and the introduction of a small business tax system.

$\checkmark$ Simplification of the personal income tax and better integration of the different types of income that comprise it (particularly rental and business income) and alignment with the corporate income tax.

$\checkmark$ A full review of excise taxes with a view toward simplification, increased rates, consistency with regional directives, and above all reform of the petroleum pricing mechanism.

$\checkmark$ Improvement of solutions already advanced in connection with VAT and continued reform of the VAT, in particular adaptation of the VAT to important economic sectors such as bank intermediation and telecommunications.

8. The administration should also focus its attention on other objectives to improve the business environment, including: (1) reduction of taxes on transactions and investments to facilitate trade (reform of recording fees, stamp taxes, business license taxes, and other minor taxes that burden transactions and investments); (2) assistance to businesses in understanding their rights and obligations (development of communications with businesses and business representatives, ${ }^{3}$ simplification and modernization of procedures, improved appeal procedures, professionalization of tax and customs administration staff, etc. During the meeting with the Malian National Employers Council (CNPM) and economic operators, all of these points were discussed at length.

\section{Position of the tax administration}

9. The crisis that afflicted Mali in 2012-2013 primarily affected the operations of offices located in the northern regions, whose share of tax receipts declined from 1.1 percent in 2011 to 0.5 percent in 2012 and first quarter 2013.

10. The impact of the crisis on the activities of economic operators was not assessed. According to information provided by the Directorate General of Medium-Sized Business Taxpayers (DME), 52 businesses reported that they had discontinued operations.

11. Regarding the functioning of the tax administration, apart from the northern regions (Gao, Kidal, and Timbuktu), whose personnel were redeployed in other regions, activities continued uninterrupted and the implementation of reforms continued.

\footnotetext{
3 The establishment of a framework for dialogue and exchanges and a partnership between the CNPM, the DGI, and the DGD to train business leaders, begun in 2012, is an initiative that should be continued and promotes voluntary tax compliance.
} 
12. To address priorities, an action plan was prepared for the period December 2012 to December 2013, based on the following three pillars: (1) improving the tax administration's image by focusing on the priorities of strengthening personnel expertise, compliance with rules of ethics, and strict application of tax laws; (2) delivering quality services to taxpayers through improvements in the delivery of information (customer service, dissemination of procedures manuals, etc.); and (3) increasing the tax administration's efficiency to manage and expand the tax base through automation of procedures and the introduction of results-based management.

13. Since the 2011 FAD mission, significant measures have been adopted including the elimination of VAT withholding at source, revision of the VAT threshold, revision of the business turnover threshold used to delimit the operational offices' responsibilities, a study of a simplified tax system for small businesses, and the start of analysis of tax expenditure (see Annex 2). All of these points are examined in the body of this report.

\section{Position of the customs administration}

14. The March 22, 2012 coup was accompanied by the sacking and pillaging of DGD central directorates and numerous customs bureaus, including the IT system and vehicles. Customs activities also declined by 16 percent of imports in 2012, notably due to the Economic Community of West African States (ECOWAS) embargo and the conflict in Northern Mali, which compelled the administration to move personnel to the South.

15. In this extremely critical context, the DGD took immediate measures to ensure continuity of operations and the collection of duties and taxes: it opened temporary bureaus, implemented procedures manuals, and installed a backup server. Ultimately, customs receipts were little affected by the situation (cf. Table 1).

16. Following the appointment of a new director general in September 2012, the activities of the steering committee resumed and significant reform initiatives were launched. These led to the implementation of the new organizational structure and the January 2013 adoption of a number of texts defining the functions and authorities of the various offices, the personnel management framework, and the rules of professional conduct, as well as the 2013 operational action plan pursuant to the 2011-2015 strategic plan.

17. The implementation of the reforms program provided by the strategic plan resulted in important and remarkable achievements in a difficult environment. The notable achievements included: (1) restructuring of the training center and implementation of an extensive training plan; (2) strengthening internal control by the internal control bureau (BCI) as well as through supervision; (3) the creation of the transit control bureau and procedures and systems to secure regional movements of goods; (4) simultaneous capacity strengthening in control of commercial operations and measures to prevent fraud and cross-border crime; and (5) the promotion of trade facilitation and partnership with business through the creation of a specialized directorate. 
18. During the course of its meetings, the mission observed a clear division of tasks between offices, effective supervision and coordination of units, and an overall clear improvement in the customs administration operations.

\section{E. Key challenges faced}

19. Several challenges should be taken into account to continue modernizing the tax system and administration and significantly improve the collection of tax and customs receipts.

20. Tax transition. ${ }^{4}$ In the area of public financial management, the second phase of the 2011-2015 Government Action Plan to Improve and Modernize Public Financial Management (PAGAM-GFP) was launched in 2011. The plan addresses four key objectives: (1) the transition from a tax system based on customs duties to a system geared toward domestic resources; (2) development of a public expenditure system that operates in program budget mode; (3) systematic reform of executive, legislative, and judiciary controls; and (4) transfer of authority and resources to local governments. As to the first point, despite improved performance by the tax base and collection offices, the tax ratio remains below 15 percent compared to a WAEMU community norm of 17 percent.

21. Legislation adapted to real objectives. Legislative reforms will require changing the very architecture of the tax system. For example, changes in personal income tax rates should result in a system that is consistent with the corporate tax rates and small business tax rates (currently under review). Therefore, while it is still possible to make multiple specific adjustments (in particular to define the corporate and IBIC tax bases), the authorities should have a genuine reform strategy that goes beyond a simple list of amendments to the General Tax Code (CGI).

22. Control of exemptions and monitoring of tax expenditure. Tax exemptions remain a weakness for Mali's tax system. Controlling tax exemptions and assessing their impact is indispensable to ensure coherence in the tax system and improve tax and customs administration performance (cf. below). Above all, the reform of tax incentives will require a clearly expressed political will and an explicit, realistic strategy for gradual implementation. It will not be a matter of simply eliminating all exemptions, but rather to identify objectives and prepare a transition strategy according to measures and the respective clientele.

23. Control of the tax base. Improving voluntary taxpayer compliance remains a significant challenge, particularly for the DGI with respect to VAT. The VAT, which generates roughly 35

\footnotetext{
${ }^{4}$ The reduction of tariff receipts associated with the commitments assumed by Mali and the WAEMU member countries to establish the economic and customs union should be offset by a significant improvement in DGI performance in terms of raising domestic tax revenue.
} 
percent of tax receipts, is paid by less than one-fourth of the businesses that owe VAT (the great majority report a VAT credit or no activity).

\section{F. Objectives for continued reforms}

24. The administrations and authorities take ownership of reforms. The measures already implemented in terms of tax policy and tax and customs administration attest to a genuine willingness to change. However, continued implementation of the reforms needed to modernize the tax system and strengthen the capacities of the implementing administrations will require planning. The customs administration, which has a strategic action plan for the period 2011-2015, could update it by incorporating the mission's recommendations. The DGI, in turn, should develop a reform plan for the next three years.

25. The presentation of reform programs, adopted by the authorities and accompanied by an implementation schedule and communication plan, is a key prerequisite to establishing a technical assistance program with the IMF. ${ }^{5}$ An action plan of this type should also include a detailed description of the data available for analysis. IMF technical staff will be available to comment on the plan, but full and complete responsibility for preparing it rests with the authorities.

26. The tax and customs policy and administration action plans should be an integral part of the PAGAM and its public finance component, which is the second phase of the Canadian development agency's Project to Support Domestic Revenue Collection (PAMORI). ${ }^{6}$ In fact, the US\$18.5 million PAMORI budget could be oriented according to the priorities examined by the report.

27. Control of the identified taxpayer population of which the majority of small and medium-sized businesses fail to comply with their tax obligations, and expansion of the tax base by reducing exemptions ${ }^{7}$ and identifying additional sources of revenue (cf. following sections).

28. Redoubled efforts to prevent tax and customs fraud and cross-border crime through determined efforts to create databases and collect information and ensure that it is utilized by

\footnotetext{
5 See, inter alia, “Grands Défis et Opportunités Économiques du Mali” (Mali’s Major Economic Challenges and Opportunities) presented in Bamako on March 18, 2011 by Mr. Dionké Diarra, Director General of Taxation.

${ }^{6}$ However, a great deal of uncertainty remains as to the program start date, given that the Canadian development agency has suspended assistance until the situation in Mali returns to normal.

${ }^{7}$ To this end, Mali could follow the example of the 2012 tax reform in Senegal, which eliminated all tax measures not provided in the General Tax Code (including provisions of the Investment Code) in exchange for tax credits for investment. These types of measures are much more consistent with the Malian authorities' stated objective of stimulating investment.
} 
specialized, well coordinated mobile units. Preventing fraud associated with commercial imports will call for heightened post-clearance controls and greater precision in technical matters.

29. The establishment of service administrations by developing partnerships with economic operators and facilitating administrative measures to increase voluntary taxpayer compliance, so that the DGI and DGD fulfill their roles in improving the business environment and supporting economic growth.

30. Modernization and simplification of procedures by making use of: (1) the migration to the latest version of the ASYCUDA World system, to optimize processes, secure procedures, and prepare to fully automate customs operations; and (2) the partnership with the Canadian development agency to continue development of the DGI information processing tool.

31. The authorities have presented a request for technical assistance in connection with programs supported by several development partners. The mission believes that subject to available financing capacities, the Malian authorities and administrations concerned meet the conditions to receive technical assistance under (1) the Policy and Administration Topical Trust Fund (TPA-TTF); and (2) the Managing Natural Resources Wealth Topical Trust Fund (MNRWTTF).

\section{If the authorities' request is accepted, the technical assistance could address three} key areas:

$\checkmark$ tax policy: (1) tax exemptions, incentives, and expenditure; (2) taxation of business and individual income; (3) indirect taxes (VAT and excise tax); and (4) stamp tax, recording fees, business licenses, and other taxes.

$\checkmark$ tax administration: (1) simplification and modernization of procedures; and (2) the implementation of tax procedures (inspection, expansion of the tax base, management of outstanding taxes).

$\checkmark$ natural resources: (1) legislation applicable to natural resources; (2) the administration of revenue generated by the exploitation of natural resources; and (3) statistical monitoring of natural resource exploitation (see mission paper on natural resource management, attached to this report).

\section{CONTINUEd REForm OF THE TAX SySTEM}

33. Certain measures proposed by the 2010 FAD mission, which are reviewed below, could be incorporated into the next budget law.

\section{A. Taxation of corporate and individual incomes}

34. Numerous challenges identified by the 2010 FAD report remain: (1) taxation of the agriculture sector, which is not covered in the corporate tax/IBIC system. The sector receives 
preferable tax treatment despite the existence of large businesses and modern farm operations; (2) tax losses, which can still be carried forward for three years instead of the recommended five; (3) deductions for interest expense are not yet limited to a percentage of expenses or otherwise capped in accordance with international standards limiting the effects of undercapitalization, particularly for extractive businesses; (4) other deductible expenses should also be limited, such as mining royalties, license fees, and intra-group charges for services rendered; (5) investment companies continue to be exempt from corporate income tax; and (6) the alternative business income tax has yet to be reformed.

35. Certain of these challenges, which call for in-depth analysis, should be addressed over the medium or long term. They involve reform of agriculture sector taxation, limitations on deductible interest expenses, and the implementation of an alternative minimum business tax (impôt synthétique). By contrast, reforms concerning tax losses carried forward, investment companies, and limitations on other expenses should not present difficulties, particularly insofar as the treatment of these issues is largely standardized in most countries. The change would be particularly simple in the case of investment companies, since there are presently no investment companies established in Mali. Accordingly, these three measures could be included in the 2014 budget law.

\section{In regard to taxing individuals, the $\mathbf{2 0 1 0}$ report recommended reform of tax}

brackets (thresholds and rates). This recommendation was based on the limited revenue generated by the tax. A reform exercise will entail studying the impact of all taxes on individual income (including taxes on the wage bill) in order to measure the effects of taxes on work incentives. The analyses should be based on individual data and simulate the effects of income taxes under several scenarios. Clearly, such a task could not be accomplished by end-2013. It should, however, be one of the priorities of the action plan. At the same time, calculation of the impact of individual income tax reform is liable to be complicated by the lack of relevant data: while automated files exist for all public sector employees, private sector employee data is maintained in paper format at this time at the large and medium-sized business taxpayer offices.

\section{The calculation of the alternative minimum business tax has not changed since the}

2010 FAD mission. The schedule of rates remains the same as in 2010, with 219 professional categories. Application of the schedule can only be negotiated with the offices given the necessarily incomplete nature of the categories and the multiple activities of numerous operators. Improving voluntary compliance by small businesses will require improvements to this tax.

\section{B. VAT and excise tax}

38. Major reforms are still needed to improve VAT administration. The system of refunding VAT credits was aligned with good practices but significant problems remain, some of which could be resolved in the 2014 budget law. For reasons including efficiency and equity (see the 2010 report), the reduced rate should be eliminated and not replaced by exemptions. The procedure for refunding credit through deduction from DGI gross receipts could also be handed 
no later than end-2013. Once the question of VAT refunds is settled, the 2014 budget law should establish that businesses subject to sector codes will also pay VAT.

\section{At the same time, certain major changes should be analyzed in the context of tax} reform. ${ }^{8}$ The application of VAT to petroleum products based on retail prices (with or without prepayment mechanisms) and the ability to deduct VAT (probably with restrictions) should be examined in detail. The same applies for the application of VAT to key sectors of the economy such as banks, insurance, and telecommunications - modifications that require adjustments to other taxes (the tax on financial activities, tax on insurance, etc.). Agriculture should also be subject to VAT, particularly insofar as the application of the threshold excludes the majority of farmers, who are small operators. Tax exemptions also warrant detailed consideration.

\section{Stamp tax, recording fees, business tax, and other minor taxes}

40. A simple, stable tax and regulatory environment, quality public infrastructures, and reliable legal guarantees at reasonable cost (in terms of money and time) are essential ingredients to economic development. In this regard, Mali imposes multiple taxes on transactions, resulting in significant management costs (in terms of time and administrative resources) for taxpayers. Recording fees and stamp taxes, which were not addressed by the 2010 FAD mission, will be briefly discussed in this section.

41. Recording fees are taxes on legal instruments required to be recorded. They apply to transactions or events requiring the preparation of legally enforceable documents (marriage contracts, sentences, deaths, etc.). The rates are fixed where there is no transfer of ownership (between CFAF 1,250 and CFAF 6,000), and proportional to the value in question where property is transferred (20 percent of the selling price of a business, 15 percent of the price of the building, etc.).

42. While recording fees offer legal certainty with respect to instruments duly recorded by the government, stamp taxes do the same for civil and judicial instruments and accounting records in general that are likely to be produced in legal actions. The tax is generally fixed (between CFAF 2 and CFAF 6,000), but can also be proportional, particularly for certain

\footnotetext{
${ }^{8}$ VAT for banks would not apply to gross interest and would be assessed on profits. It is possible, for example, to assess VAT on services invoiced (with a proportional deduction of input VAT) and provide for a reduced rate for total wages, salaries and profits, which represent a measure of the added value of financial intermediation (the method employed in the Canadian Province of Québec and in Israel). Such a system would comply with WAEMU directives and best international practices (see, e.g., International Monetary Fund, "A Fair and Substantial Contribution by the Financial Sector," Final Report for the G-20, June 2010). Several other systems are also possible (see, e.g.,: Zee, Howell (2006), "VAT treatment of financial services: A primer on conceptual issues and country practices," Intertax, Vol. 34, pp.458-474). In all cases, the current tax on interest should be eliminated.
} 
financial instruments. Stamp tax is imposed on the following transactions ${ }^{9}$ : (i) the stamp of the dimension required on legal, judicial, and notarized instruments; (ii) the proportional stamp for certain financial instruments such as promissory notes, bills of exchange, and warrants (0.6 percent of value); (iii) the receipt stamp paid on movie tickets, travel fares, and checked baggage; (iv) transportation contract stamps, charged for documents evidencing the transport of merchandise; and (v) stamps relating to the issuance of certain documents: passports, police records, drivers licenses, identification cards, and the Intention d'Exportation (a document issued by the National Directorate of Trade and Competition (DNCC)).

43. Since the amounts of recording fees are prohibitive, they are seldom applied. Such recording fees, proportional to the value of contracts without limitation, encourage the contracting parties to dispense with recording instruments to reduce transaction fees; this weakens the legal guarantee the recording fees are intended to provide. It can also lead to systematic understatement of transaction amounts, resulting in substantial tax losses, particularly in regard to capital gains tax.

44. The stamp tax has become a catch-all for various types of government revenue. It includes fees for government services (passports, etc.), consumption tax (on movie tickets), financial taxes, etc., that are no longer directly linked to the primary function of the stamp tax.

45. The stamp tax on cash transactions is in fact a turnover tax, which no longer serves that purpose since the introduction of VAT. It applies only to formal businesses that maintain a transactions register, which penalizes firms that issue invoices as proof of payment. The stamp tax is therefore a tax on the formal sector. ${ }^{10}$ More generally, recording fees and stamp tax are detrimental to transactions that facilitate efficient allocation of resources between economic actors.

\section{Several countries recently reduced recording fees, particularly on real estate}

transactions. Senegal reduced recording fees for a number of types of transactions in connection with the December 2012 reform, particularly the fees on real estate transactions, which were reduced from 15 percent to 10 percent. The Central African Republic did the same in 2011, reducing the rate from 15 percent to 7.5 percent. Senegal also overhauled its stamp tax in 2012 .

\section{The business income tax (patente) is a tax assessed on the practice of a profession,} trade, or productive activity. It is collected by the central administrations and transferred to local governments. It includes a fixed component and a proportional component of 10 percent of the rental or market value. Since the rental value includes equipment [and] fixtures, the

\footnotetext{
9 Source: CGI, Overview of Tax Policy.

${ }^{10}$ In this regard, the amount of tax adjustments for noncompliance is much higher than the amount of the stamps themselves and results in considerable adjustments, on the order of CFAF 1 billion, while [relatively few] economic operators are familiar with the details of the stamp tax on cash transactions.
} 
proportional component becomes in fact a tax on investment, and could represent a substantial levy in the case of high capital intensive projects. Moreover, the base of the rental value is already directly or indirectly taxed in the form of taxes on property income and/or property taxes (assessments on improved and unimproved property). The history of the business income tax indicates that it was initially a type of alternative minimum tax that served to tax income (with the rental value and right to practice serving as an indicator of income), although a tax of this type already exists in Mali. While logical, the elimination of the business income tax is impossible in the short term because it provides substantial tax resources for local authorities. Any reform of the business income tax should therefore be combined with reform of property taxes, which should become the basis of local government revenue. This is therefore a vast undertaking and that depends, inter alia, on fiscal decentralization and the capacity of DGI and local authorities to manage property taxes.

\section{Recommendations}

- $\quad$ Prepare an action plan detailing the context and rationale for tax policy reform, the objectives sought, the measures contemplated, and the implementation schedule. A communication plan vis-à-vis operators should also be included, as well as a plan for coordination with reform initiatives in the area of public finance (e.g., PAMORI). The action plan should be fully synchronized with the tax administration reforms.

- $\quad$ Lengthen the period to carry over tax losses to at least five years.

- $\quad$ Limit the deductibility of interest in determining taxable earnings.

- $\quad$ Align the taxation of investment companies with the general tax provisions.

- $\quad$ Eliminate the reduced VAT rate and replace it with the standard VAT rate, without replacing it with exemptions.

- $\quad$ Accelerate the refund of VAT credits through deduction from DGI gross receipts (with minimum control by the Treasury).

- $\quad$ Apply VAT to businesses governed by sector codes.

- $\quad$ Revise excise tax [rates] in accordance with the 2010 FAD report.

- $\quad$ Adopt a government position on the issue of recording fees, stamp tax, and business income tax, and include this position in the action plan. 


\section{Priority Measures to Strengthening Tax Administration}

48. This section will review the priority measures to continue modernizing the tax administration. The priority should address four areas in which progress can be quickly achieved: (1) control of tax obligations; (2) tax audits; (3) expansion of the tax base; and (4) organization of offices and management of outstanding tax liabilities.

\section{A. Control of tax obligations}

49. A review of reporting practices in regard to VAT (a tax that represents over one-third of tax receipts) should be one of the DGI priorities. An analysis of the reporting situation from January 1, 2012 to May 31, 2013 shows that:

$\checkmark \quad$ large businesses file their tax returns on time, but the nonfiler rate remains quite high for medium-sized businesses ( 26 percent) and small businesses (over 70 percent); and

$\checkmark \quad$ only 27 percent of large businesses effectively pay VAT, given the large number of VAT credits reported year after year. This rate falls to 20 percent for medium-sized and small business taxpayers.

50. Three measures could be taken to quickly change the behavior of nonfiling taxpayers and increase VAT receipts:

(1) Launch a campaign to audit VAT credits, beginning with businesses whose activities should not continually generate VAT credits (especially commercial activities and service providers). It was observed that the elimination of VAT withholding at source, begun in January 2012 , has not brought about a visible decrease in the number of businesses with credits. The share of businesses with credits remains excessively high, representing 73 percent of large businesses and 82 percent of medium-sized businesses (see section B below for proposed measures to audit VAT credits).

(2) Strengthen monitoring of compliance with reporting obligations by following up systematically with nonfilers and having the tax authorities determine (off-site or on-site) the tax payable by chronic nonfilers. The nonfiler rate should not exceed 10 percent for medium-sized businesses and 15 percent for small businesses.

(3) Revise the scope of application of VAT by applying the VAT threshold to all taxpayers irrespective of the nature of their activity or legal status, as recommended by previous IMF missions. This should include, for example, legal entities. Nothing distinguishes an activity practiced directly by an individual from that practiced by the same individual operating as a sole proprietorship (legal entity). The change in status does not provide the individual any additional capacity to meet the complex obligations of the system of taxation based on actual income. Accordingly, over 80 percent of such businesses are nonfilers. The alternative minimum tax provisions are better suited to these types of taxpayers, who represent the great majority of legal 
entities administered by the individual taxpayer offices (centres des impôts, CDIs). This measure would allow the offices to concentrate their efforts on the real objectives in terms of collection of VAT receipts. Obviously, businesses whose turnover is below the VAT threshold should have the option of choosing to pay VAT.

51. Complementary measures should also be taken, as recommended by the 2011 mission, to simplify tax obligations, lessen the administration's workload, and facilitate taxpayers' compliance with their tax obligations. Three measures are needed in particular:

(1) Elimination of tax assessment notices. As the Malian tax system is based on the principle of voluntary filing and payment, there is no justification for the use of assessment notices. Since the taxpayer has declared and paid his taxes, it is pointless to send him a document to advise him of the amount of taxes payable. A modern administration no longer issues notices of assessment except for those generated by a tax audit or for taxes not paid at the taxpayer's initiative (e.g., property taxes).

(2) Revision of the simplified tax system (RSI) applicable to businesses with turnover between CFAF 30 million and CFAF 100 million, which is paradoxically more complex then the system of taxation based on actual earnings applied to businesses whose turnover exceeds CFAF 100 million. ${ }^{11}$ The principal simplification would be to introduce quarterly VAT reporting.

(3) The implementation of procedures for payment via bank transfer, potentially followed by the introduction of online reporting and payment, depending on technical capacities (beginning with very large businesses).

\section{B. Measures to improve the effectiveness of tax audits}

52. Tax audits are conducted by the DGE for large businesses, the DME for medium-sized businesses, and the regional directorates for small businesses. The procedure used is based on a general verification (VG), which is an audit of all taxes, duties, and assessments payable by a taxpayer over a period of several years. During the period January 2010 to December 2012, the financial results of tax audits were weak (less than 3 percent of DGI receipts).

53. Improving the efficiency of tax audits should be another priority for the authorities, who could address the resources allocated to inspections as well as adapt inspection procedures to address real tax objectives.

54. The coverage of tax audits is limited. Currently, between 10 percent and 12 percent of large and medium-sized businesses are audited annually. Given the extent of the risk of fraud, which generally increases during periods of crisis, the proportion of businesses audited should be

\footnotetext{
${ }^{11}$ For example, a firm subject to the simplified tax system files 13 returns (12 provisional monthly returns and a final annual return), while a firm subject to the standard tax system files 12 monthly returns.
} 
on the order of 25 percent for large businesses and 15-20 percent for medium-sized businesses. Also, as indicated above, a large number of businesses (of all categories) report the clearly irregular situation of continual VAT credits. Regular audits will be needed to bring this situation under control.

55. To make the best use of the DGI's limited audit staff (of about 70) to expand the coverage of tax audits, the DGI could make greater use of ad hoc audit procedures, which are currently used only in connection with refund of VAT credits, and revise the objectives assigned to auditors. Table 3 presents several standards for tax audits.

Table 3. Examples of standards for tax audits

\begin{tabular}{lccccc}
\hline & $\begin{array}{l}\text { Ad hoc VAT } \\
\text { audits }\end{array}$ & $\begin{array}{l}\text { Number of ad hoc } \\
\text { audits per } \\
\text { inspector }\end{array}$ & General audits & $\begin{array}{l}\text { Number of } \\
\text { general audits } \\
\text { per inspector }\end{array}$ & VAT refund \\
\hline Large businesses & 5 days & $20-25$ per year & $30-90$ days & $8-10$ per year & $3-5$ days \\
Medium-sized businesses & 3 days & 25-30 per year & $30-45$ days & $10-12$ per year & $2-3$ days \\
Small businesses & n.a. & n.a. & $5-10$ days & 12-15 per year & n.a. \\
\hline
\end{tabular}

Source: IMF

56. The staffing allocated to tax audits generally represents between 20 percent and 30 percent of the total tax administration staff (compared to less than 10 percent for the Malian DGI).

57. Advantages of ad hoc audits. This procedure allows authorities to respond quickly to nonfiling situations and correct anomalies detected, particularly by the management offices. As observed by the 2011 FAD mission, the main objective of ad hoc audits is to improve taxpayer behavior with respect to reporting and payment of taxes. This objective is assessed in terms of global impact. The administration's increased presence at businesses produces this outcome to a far greater extent than an immediate tax adjustments following an audit, particularly for VAT and the tax on wages and salaries. This frequent presence in connection with limited audits of several well-targeted operations over a short period of time is intended to correct errors, provide information to accounting and management personnel, and deter fraud (see Diagram 1 comparing general verifications and ad hoc audits). 


\section{Figure 1. Advantages of ad hoc audits}

Type of audit

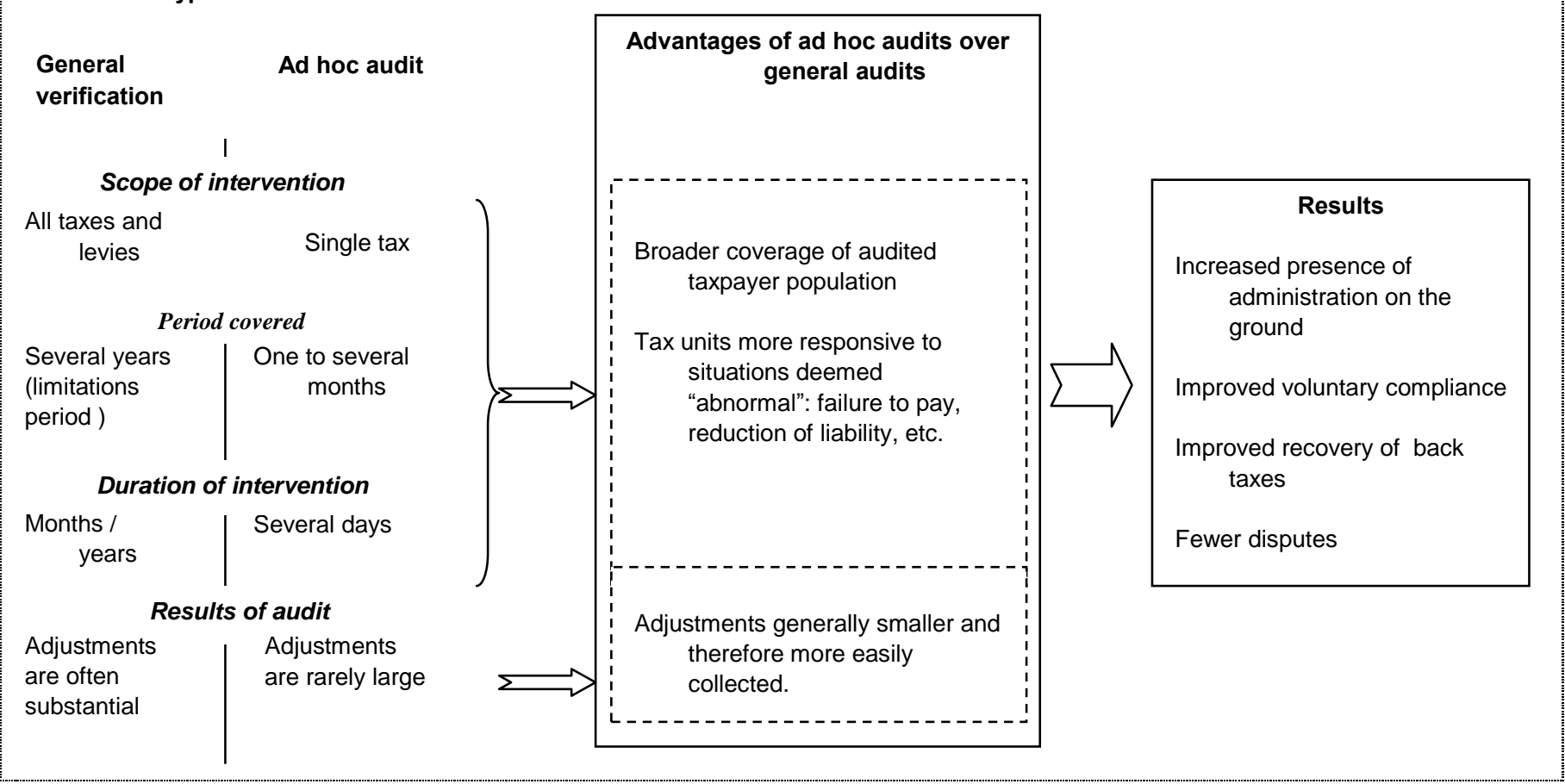

58. Supervision of tax audits should be strengthened. In the absence of a team leader, the supervision of auditors is performed by the Audit Support Division (DAV), which is a unit of the subdirectorate in charge of tax audits. The supervision is conducted in the form of "quality assurance." The DAV receives for analysis and opinion all documents relating to the procedure (notice of adjustment, confirmation of adjustments, audit reports, etc.) for all audits and verifications conducted by the DGI. As observed by the 2011 FAD mission, the review of all audit records lengthens the procedure, often by several weeks. Since the solution is not to increase the number of reviewers, the following measures are proposed:

(1) Auditor should be organized into teams managed by a team leader whose principal activities are presented in Box 1. As a general rule, the team leader supervises 10 to 12 auditors. Two team leaders should be appointed in advance at the DGE and the DME.

(2) Quality assurance should be refocused on an analysis of audit operations after completion, using sampling. Performing quality assurance checks for all auditors, including the most productive and experienced auditors, pointlessly consumes resources that could be used, for example, for on-site reviews and audit missions. 


\section{Box 1. The role of an audit team leader}

The audit team leader is essentially the head of the team but also interfaces with the headquarters offices.

$\checkmark \quad$ The team leader:

- $\quad$ ensures that the auditors are familiar with new legislative measures;

- maintains ongoing contact with auditors in preparing and conducting missions;

- $\quad$ regularly monitors the progress of procedures (phases, deadlines, etc.);

- $\quad$ receives all documents related to the audit procedure (notices, confirmations, etc.);

- $\quad$ provides an opinion on tax adjustments and arbitrates as necessary, after consultation with headquarters offices;

- $\quad$ holds regular meetings with the auditors;

- $\quad$ provides an opinion on disputes and serves as arbitrator; and

- $\quad$ evaluates the auditors' work.

$\checkmark \quad$ The team leader interfaces with the directorate general to:

- $\quad$ explain the strategy chosen by the headquarters offices;

- $\quad$ report difficulties encountered in the course of the tax audit; and

- $\quad$ propose measures to improve the effectiveness of its services, procedures, and methods.

$\checkmark \quad$ While the team leader does not conduct audits,

- he may assist a new auditor; or

- take part in an audit that presents major difficulties (taxpayer behavior, lack of experience or expertise on the part of the auditor).

\section{Measures to improve the research activity and expand the tax base}

59. The expansion of the tax base is also a priority for the authorities. Several years ago, the DGI strengthened the Research Division's research and investigation offices. In addition, the Joint Economic and Financial Intelligence Committee was created by interagency order ${ }^{12}$ in March 2012 to facilitate the gathering and use of information for tax purposes (an initial report of the Committee's activities will be completed in September 2013). To increase the effectiveness of research and investigation offices to expand the tax base, three measures will be required: (1) clarify the roles of the various participants; (2) develop a genuine research strategy; and (3) evaluate results on a regular basis.

60. Clarification of participants' roles. The 2011 FAD mission had discussed with the authorities the possibility of increasing the effectiveness of anti-fraud measures and exchange of information by creating a joint task force among several ministries and directorates. Annex 3 of the report stated that:

12 The members of the committee were Ministry of Economy and Finance; the Ministry of Industry, Investment, and Trade; the Ministry of Housing, Land Affairs and Urban Development; and the Ministry of Social Development, Solidarity, and the Elderly. 
(1) The main objective of a joint task force is to establish close cooperation between its members (in particular, the DGI, the DGD, and the Directorate General of the Treasury and Public Accounting (DNTCP)) to conduct investigations to bring anti-fraud practices in the tax and customs areas up to date. The task force could include other administrations as needed for particular operations concerning mining operations, for example;

(2) The task force should support tax audits and customs inspections by conducting investigations to uncover fraud associated with regional and international trade (particularly fictitious exports and fraudulent imports), ensure that special provisions are correctly applied (e.g., by monitoring the destination of exempt goods), and expand the tax base through investigations in the area of informal activities;

(3) The activities of the task force should not duplicate those of other DGI and DGD research and investigation offices. For example, regarding the collection of tax-related information, the joint task force is not intended to replace the DGI research and investigation offices or the audit offices. Accordingly, its purpose is not to conduct tax audits or use the ASYCUDA information, for example, to reconcile imports and exports with the turnover figures reported by the businesses concerned. In addition, the task force should share the DGI database, to which it will contribute the information it collects. However, tasks not performed by the research offices themselves (even if provided as part of their activity) could be assigned to the task force. For example, the joint task force could conduct the right of inquiry procedure provided by article 549 et seq. of the CGI. The procedure is intended, inter alia, to secure VAT receipts by enabling the tax and customs administrations to ensure that VAT was assessed on goods in circulation or released for consumption, either at the customs border at the time of import, or at the time of sale on the domestic market. Finally, investigations could be assigned to the task force to detect any mining-related trafficking.

61. Therefore, the use of information originating from the financial administrations (customs, the Public Treasury, etc.) should come within the responsibilities of the DGI research team using the automated link between ASYCUDA and the automated tax management system SIGTAS.

62. Once the research team capacities to collect and process tax information have been strengthened, the role of the Committee should be refocused to prevent its missions from duplicating those normally assigned to a research office. In the area of information collection, then, it would intervene to facilitate the collection of information from sources difficult to access, such as banks and financial institutions, insurance companies, the central bank, etc. It would also supervise the activities of research offices in order to improve their effectiveness.

63. Develop a strategy for collecting and utilizing information. Efforts were made in recent years to improve the identification of individual and business taxpayers based on a taxpayer identification number (NIF). While the objective of data collection procedures was to centralize data based on the NIF, two comments are in order regarding data and data processing: 
(1) audit was not integrated in the collection process from the start. The database is essentially utilized by the audit offices after programming. However, one of the primary objectives of a research office is to contribute to the programming of tax audits; and

(2) the research offices do not have access to information from tax records.

64. Ultimately, the audit program is largely based on raw information (i.e., information not reconciled with tax records) collected by the research team. This approach gives rise to numerous difficulties such as the following: (1) businesses are programmed for tax audits without being located; (2) information is exploited needlessly because it has already been reported by the businesses; (3) programming is highly random; and (4) a large amount of information is never used.

It is imperative that the information collected by the research offices be leveraged to expand the tax base and effectively combat fraud. The approach recommended to make use of information collected aims to: (1) focus efforts on the real objectives; (2) transmit useful information to the audit and management offices; and (3) quickly use the information collected. Box 2 presents a methodology for the use of tax-related information.

\section{Box 2. Methodology for comparing data from different sources for programming purposes}

The quality of tax audits largely depends on the quality of programming, which is in turn highly dependent on the activity of the research and investigation offices.

Information gathering for tax purposes is the primary mission of a research office, which must:

$\checkmark \quad$ Necessarily focus its activities on gathering the most useful information, which means limiting crosschecks based on a threshold (e.g., CFAF 1 million), which could, however, be initially limited to the VAT threshold.

$\checkmark$ Ensure that the information obtained is quickly put to use. Experience shows that much information is no longer usable after several months (primarily information identifying large businesses concealing their activities in the informal sector), because the business has either disappeared or arranged for its own insolvency.

$\checkmark$ Transmit useful information. A research office is not a mere data transmission service. It must reconcile the information collected with tax data known to the DGI - either directly through a ASYCUDA link or by consulting tax records - and make recommendations in accordance with the following principles:

- If the managing office has no knowledge of the business or it is taxed under the single flat tax (IFU) provisions but the information relates to an activity taxed on actual earnings, a form is prepared recommending an audit.

- If the business is taxed based on actual earnings, the office ensures that the reported turnover corresponds to the amount indicated by the information collected: (i) if the turnover declared is less than the amount indicated by the information obtained, an audit recommendation form is prepared; or (ii) if the turnover declared is greater than the amount indicated by the information obtained, a validation form (bulletin de recoupement) is prepared for filing in the business's tax record. 
65. Analysis of results. To benefit from the research offices' work and refocus their strategy if needed, it is important for the recipient offices to evaluate the use of the information obtained. This analysis should be conducted by the subdirectorate responsible for tax audits. Figure 2 presents the flow of tax-related information.

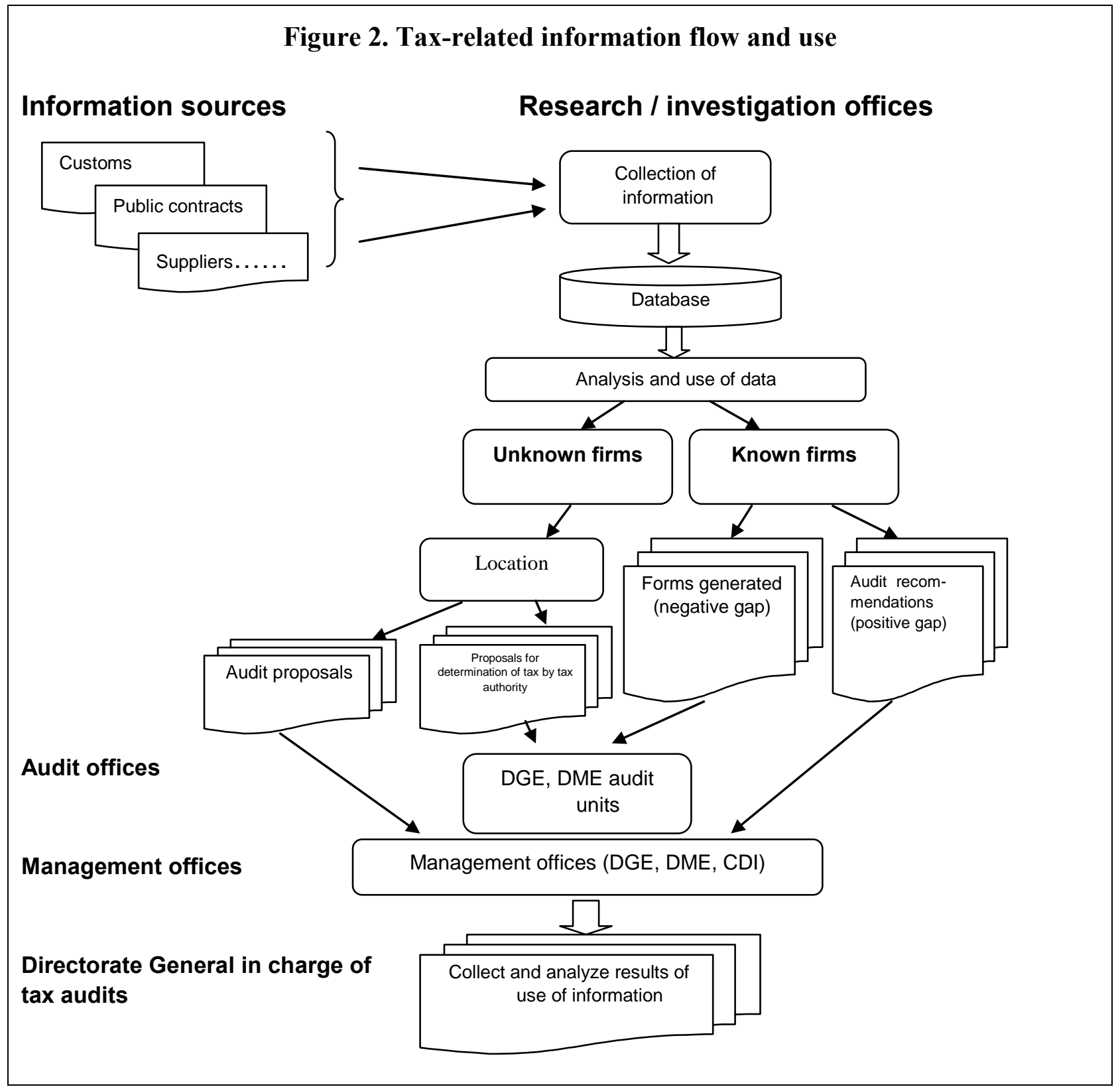

\section{Framework for elimination of VAT withholding}

66. After reaching a high of 6.8 percent of GDP in 2005 following a period of strong growth between 2000 and 2005 ( 4.3 percent to 6.8 percent), the ratio of total VAT receipts to GDP slipped to 5.6 percent in 2010. VAT receipts recovered to 6.2 percent of GDP in 2011 (Table 4) 
despite a sharp decline in growth (3.5 percent compared to 5.8 percent the previous year) following a poor harvest.

Table 4. VAT receipts, 2000-2012

(CFAF billion and \% GDP)

\begin{tabular}{|c|c|c|c|c|c|c|c|c|}
\hline & 2005 & 2006 & 2007 & 2008 & 2009 & 2010 & 2011 & 2012 \\
\hline VAT collected by DGI & $\begin{array}{l}72.3 \\
(2.6) \\
\end{array}$ & $\begin{array}{l}70.1 \\
(2.2)\end{array}$ & $\begin{array}{l}72.6 \\
(2.1)\end{array}$ & $\begin{array}{l}88.1 \\
(2.2)\end{array}$ & $\begin{array}{l}94.5 \\
(2.2)\end{array}$ & $\begin{array}{l}98.9 \\
(2.1) \\
\end{array}$ & $\begin{array}{l}115.0 \\
(2.3)\end{array}$ & $\begin{array}{l}103.2 \\
(1.9) \\
\end{array}$ \\
\hline VAT collected by DGD & $\begin{array}{c}119.6 \\
(4.2) \\
\end{array}$ & $\begin{array}{l}126.9 \\
(4.1)\end{array}$ & $\begin{array}{l}121.8 \\
(3.6)\end{array}$ & $\begin{array}{l}112.7 \\
(2.9)\end{array}$ & $\begin{array}{l}153.9 \\
(3.6)\end{array}$ & $\begin{array}{l}162.9 \\
(3.5)\end{array}$ & $\begin{array}{l}185.5 \\
(3.7)\end{array}$ & $\begin{array}{l}171.5 \\
(3.3) \\
\end{array}$ \\
\hline VAT BCEAO account & & & & & & & $\begin{array}{r}9.950 \\
(0.2) \\
\end{array}$ & $\begin{array}{r}11,779 \\
(0.3) \\
\end{array}$ \\
\hline Total VAT & $\begin{array}{l}191.9 \\
(6.8) \\
\end{array}$ & $\begin{array}{l}197.0 \\
(6.3)\end{array}$ & $\begin{array}{l}194.4 \\
(5.7)\end{array}$ & $\begin{array}{c}200.8 \\
(5.1)\end{array}$ & $\begin{array}{c}248.4 \\
(5.8) \\
\end{array}$ & $\begin{array}{c}261.9 \\
(5.6)\end{array}$ & $\begin{array}{l}310.5 \\
(6.2) \\
\end{array}$ & $\begin{array}{c}286.5 \\
(5.5) \\
\end{array}$ \\
\hline Total VAT / total receipts (\%) & 43.2 & 40.8 & 38.3 & 38.0 & 39.2 & 37.8 & 42.6 & 37.3 \\
\hline Total receipts /GDP & 15.7 & 15.4 & 14.8 & 13.5 & 14.7 & 14.8 & 14.5 & 14.8 \\
\hline Memo item: GDP & 2,829 & 3,132 & 3,425 & 3,915 & 4,233 & 4,656 & 5,028 & 5,243 \\
\hline
\end{tabular}

Source: mission calculations based on DGI and DGD data.

67. In 2012, the VAT efficiency ${ }^{13}$ fell to $(5.5 * 100) / 18=30.5$, which corresponds to the lower end of the range (30 to 40) of VAT efficiency ratios generally seen in sub-Saharan African countries. This low VAT efficiency is partially attributable to the serious crisis in Mali but also to a lack of improvement in VAT efficiency since 2005.

68. To check the already unfavorable trend in VAT receipts, withholding at source had been instituted in 2006. As recommended by the 2011 mission, withholding was eliminated for businesses managed by the DGE in January 2012. The elimination of withholding for public contracts was limited to 40 percent on January 1, 2013 and will be completely abolished on January 1, 2014.

69. Problems following the partial elimination of VAT withholding at source. The partial elimination of withholding at source was followed by a decline in VAT receipts in 2012 (Table 3 ). However, the causes of the decline are difficult to determine because the elimination of source withholding is combined with the effects of the crisis.

70. Contrary to expectations, no increase was observed in the number of VAT returns or amounts of VAT paid by businesses subject to withholding at source as at end-2011. It is therefore possible that the partial elimination of VAT withholding at source on total VAT receipts produced an unfavorable impact.

\footnotetext{
${ }^{13}$ This is the tax efficiency ratio defined by Ebrill et al., 2001, which facilitates international comparisons. The ratio measures the average VAT receipts (as a proportion of GDP) generated by one percentage point of VAT.
} 
71. The 2011 FAD mission had drawn attention in particular to the risk of loss of VAT receipts associated with the elimination of VAT withholding at source: the key risk was that businesses previously subject to withholding would consider themselves released from their reporting obligations and would not file a their VAT returns, yet they would collect net VAT once again with the elimination of VAT withholding. The risk of nonpayment is even greater considering that withholding at source contributed over 50 percent of domestic VAT (FAD report, 2011). In that context, the mission had recommended communication actions directed at businesses subject to VAT withholding and heightened, adapted audits of businesses no longer subject to VAT withholding at source. However, the administration's actions were limited to the belated (April 2013) transmittal of a letter to the businesses concerned to remind them of their reporting obligations. No audits were conducted.

72. The forthcoming elimination of VAT withholding on public contracts will further aggravate the risk of loss of VAT receipts. To mitigate the risk, it is imperative that ad hoc audits be implemented based on comparisons of data from different sources to ensure that businesses previously subject to VAT source withholding effectively pay the VAT owed.

\section{E. Other measures to improve offices' efficiency}

73. Finalize the DGI reorganization based on the principle of segmentation. The DGI reorganization began in 1994 with the creation of the DGE. It continued in 2010 with the creation of the DME. As of January 2012, ${ }^{14}$ the DGE is responsible for businesses generating turnover of over CFAF 1 billion; the DME, for businesses with turnover between CFAF 100 million and CFAF 1 billion; and the CDIs, for businesses with turnover of less than CFAF 100 million.

74. The mission supports the DGI plan to finalize the reorganization, which will result in assigning responsibility for businesses taxed on actual income to the DGE and the DME, and responsibility for small businesses to the CDIs. Ultimately, the redefinition of tax population segments could result in management rules reflected in the taxpayer classification scheme (ultimately including the creation of a category including microenterprise and revision of the RSI as recommended).

\footnotetext{
${ }^{14}$ Prior to 2012, the business turnover limits were CFAF 500 million for the DGE, between CFAF 150 and CFAF 500 million for the DME, and less than CFAF 150 million for the CDIs.
} 
Figure 3. Proposed classification of taxpayers

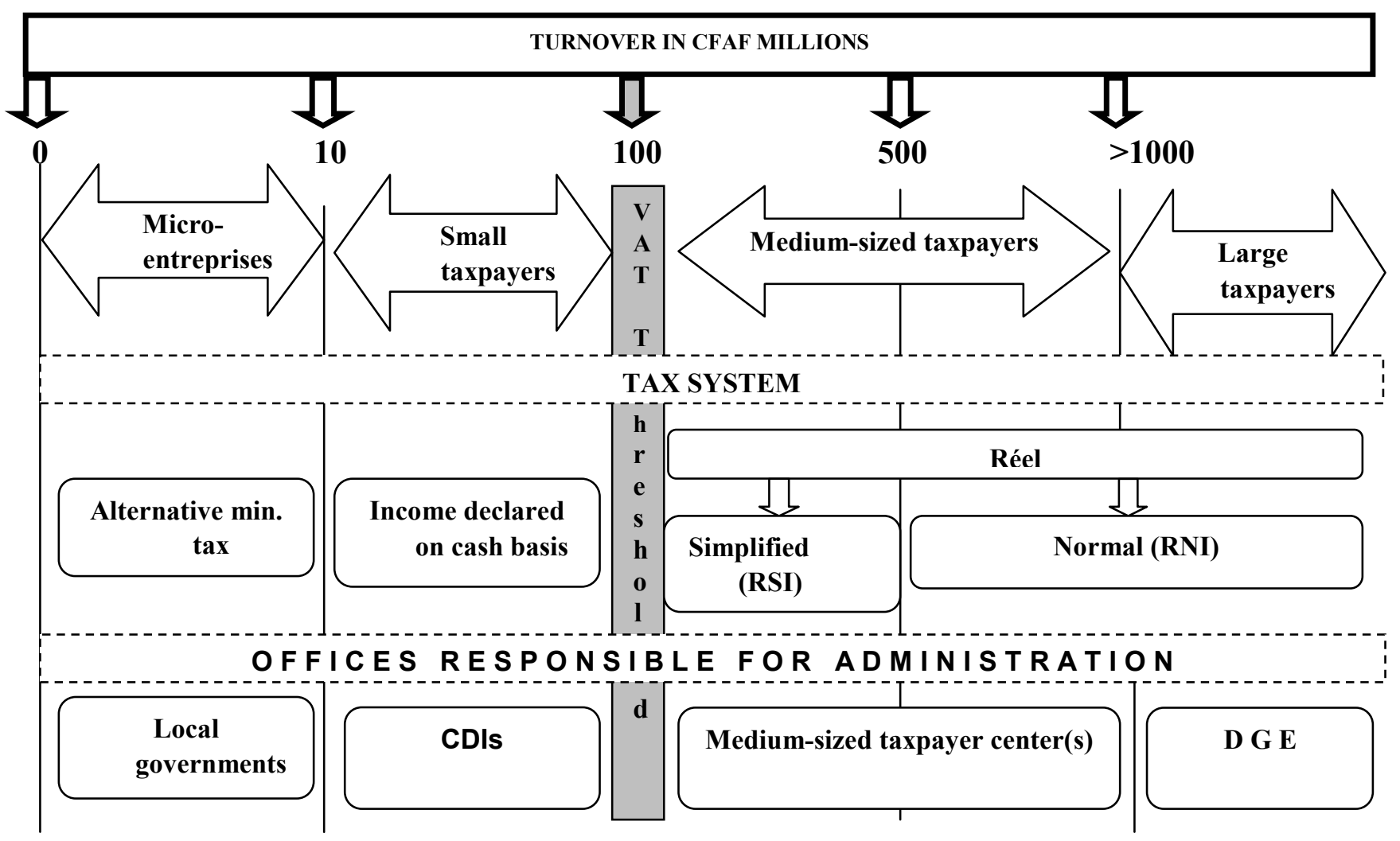

75. Improve control of outstanding taxes. Between January 1, 2011 and December 31, 2012, the outstanding taxes recorded by the DGE and DME increased from CFAF 8.4 billion to CFAF 42.4 billion. The increase is largely due to the crisis, which greatly increased businesses' difficulties in making payments, particularly for taxes assessed on a pre-crisis tax base (corporate tax and IBIC in particular).

76. The DGI should act quickly to clear tax arrears, taking the difficulties inherent to the crisis situation into consideration. To this end, the collections offices should complete a detailed analysis of tax arrears to determine the possibility of collection. Table 5 provides an example of a monitoring framework for outstanding taxes.

Table 5. Sample classification of outstanding taxes to determine "recoverability"

\begin{tabular}{|l|l|l|l|l|l|}
\hline Age of liability & $\begin{array}{r}\text { Less than 3 } \\
\text { months }\end{array}$ & $\begin{array}{r}\text { Between 3 and 7 } \\
\text { months }\end{array}$ & $\begin{array}{c}\text { Between 6 months } \\
\text { and 1 year }\end{array}$ & $\begin{array}{c}\text { Between 1 year and } \\
\text { 3 years }\end{array}$ & Over 3 years \\
\hline Type of outstanding tax & & & & & \\
\hline Dispension of payment & & & & & \\
\hline Reduction of liability expected & & & & & \\
\hline Businesses in insolvency & & & & & \\
\hline Tax liability not disputed & & & & & \\
\hline \multicolumn{1}{|c|}{ Total } & & & & & \\
\hline
\end{tabular}


77. Based on the above classification, an action plan should be prepared to implement the measures needed to clear tax arrears. Three categories of tax arrears should be defined: (1) recoverable taxes, for which collection actions should be instituted without delay; (2) taxes for which the likelihood of collection is low, for which targeted actions should be taken (e.g., requesting the authorities' assistance in case of nonpayment by government-held businesses); and (3) unrecoverable tax arrears, which will be recommended for write-off.

78. The action plan would give priority to following up on the largest tax liabilities with the best chances of recovery (for example, undisputed tax liabilities less than three months past due in the classification proposed above). During this phase, the team responsible for implementing and monitoring the action plan should also review compliance with the terms and conditions and any extensions of time granted in connection with suspended payments. It should also take all necessary measures to ensure that the processing of disputes does not delay the recovery of tax liabilities.

79. At the same time, tax collectors should propose measures to prevent the accumulation of future tax arrears. Box 3 presents the three key areas in which to intervene to limit the accumulation of tax arrears.

\section{Box 3. Measures to prevent the accumulation of tax arrears}

To avoid the accumulation of new tax arrears, the following measures could be taken:

$\checkmark \quad$ Improve the monitoring of businesses' reporting obligations: for each return filed without payment, take immediate action vis-à-vis the business.

$\checkmark \quad$ Improve tax assessments: in particular, assessments arising from off-site supervision (in particular, assessments determined by tax authorities) and tax audits (by strengthening the supervision and quality of audits and notices issued).

$\checkmark \quad$ Improve professional training: evaluate the training needs of tax collectors and personnel responsible for enforced collection and propose a training plan.

$\checkmark \quad$ Apply all legislative measures to pursue collection: in particular, increase the use of the most effective measures, such as provisional attachment measures. In addition, ensure that collection actions are carried out within the established time frames (if an action produces no results, several months should not elapse before more coercive measures are instituted).

$\checkmark \quad$ Improve procedures: ensure compliance with the terms, conditions, and extensions of time granted in connection with suspensions of payment, and revise dispute procedures as necessary to shorten collection times in case of disputes. 


\section{Recommendations}

- $\quad$ Strengthen VAT administration by: (1) improving monitoring of tax obligations in order to bring the nonfiler rate below 10 percent for the DME and 15 percent for the CDIs; (2) inaugurating a campaign to audit VAT credits; (3) apply the VAT threshold to legal entities by introducing a right to opt to pay VAT; (4) simplifying the RSI; and (5) modernizing reporting and payment procedures.

- Improve the effectiveness of tax audits by: (1) revising the auditors' objectives; (2) giving preference to ad hoc audits to verify non-filing situations and VAT credits; (3) organizing auditors into teams headed by team leaders; and (4) refocusing quality control from verification to analysis of results.

- $\quad$ Make research offices more efficient by: (1) clarifying the respective roles of the joint interagency committee and DGI research offices to avoid overlapping areas of authority; (2) defining a clear strategy for the collection and use of tax-related information; and (3) providing the research team with access to tax records and the taxpayer file.

- $\quad$ Conduct ad hoc audits, focusing first on the largest suppliers of the 50 large businesses now exempt from withholding. The audits should be based on validation using the accounting records of large businesses that withheld VAT up to end-2011.

- Implement communication actions regarding VAT reporting obligations, specifically targeting the suppliers to large businesses and all government suppliers.

- $\quad$ Provide for the capability to quickly audit effective payment of VAT by government suppliers once VAT withholding on public contracts is eliminated in January 2014.

- $\quad$ Establish a strategy to clear tax arrears based on a classification by type, age, and amount in order to determine the rate of recoverability.

\section{Priority Measures to Strengthen Customs administration}

80. The mission identified five areas in which modernization efforts should be specifically focused: (1) control of commercial operations; (2) risk analysis and anti-fraud efforts; (3) trade facilitation and partnership with business; (4) automation; and (5) resource management and supervision of staff.

\section{A. Control of commercial operations}

\section{Transit: Initiative to secure operations should be pursued}

\section{The DGD has implemented two innovative measures concerning bonded}

merchandise in transit, which is of great importance to Mali in light of its geographic isolation: (1) the introduction of a transit document covering regional routes; and (2) the creation of a transit control bureau (BCT) using a GPS-type system and mobile brigades. 
82. In May 2013, the Malian customs office at the Dakar port began creating regional transit documents (TRIE) in ASYCUDA (T1 p.m. ASYCUDA) as soon as it receives a copy of the operator's the transit declaration filed with the Senegalese customs authorities. The procedure facilitates entry to Mali and secures customs operations, since the Malian entry and destination bureaus are informed in advance. Malian customs offices have been or are being installed at other ports, and negotiations are under way to apply this procedure at other corridors. $^{15}$

\section{The framework for procedures to locate non-completed transits and apply} suspended duties and taxes should be strengthened. In particular: (1) a regulatory time limit should be established for the search process; (2) where the search process is unsuccessful, the party responsible for the transit operation should be required to pay duties and taxes as soon as the time limit expires, regardless of the existence of any fraudulent circumstances; and (3) in case of nonpayment, duties and taxes should be collected via the bond. However, the current bonding procedure appears ineffective because no cash collateral is required. A financial guarantee should be required, in an amount based on the operator's average traffic over the preceding 12 months and the average time in transit. For new importers, the amount of collateral required should be monitored and adjusted as necessary and at least monthly.

84. Trade in the informal sector calls for tighter measures. According to information obtained, groupings of miscellaneous goods not identified or poorly identified by commercial documents originate primarily from Guinea. It would be preferable to clear this traffic as close to the border as possible and unload it more frequently for comprehensive inspections. An alternative that could be considered would be to eliminate the threshold established for the inspection company and ask it to inventory and value all goods. The Guinean border is a known smuggling route for highly taxed products, especially cigarettes. This smuggling should be countered by the combined action of mobile brigades and the customs inspection offices (cf. B below).

85. The combined use of an effective position monitoring system for utility vehicles known as Ébémi ${ }^{16}$ - and mobile customs brigades to respond to incidents, will contribute considerably to securing bonded transit. Ébémi was recently implemented along the TemaOuagadougou-Bamako corridor. The mission supports the DGD initiative to apply this mechanism on all corridors. The low cost of the vehicle tags used (CFAF 12,500 per vehicle for

\footnotetext{
${ }^{15}$ Corridors from Abidjan, Conakry, Cotonou, Lomé, Nouakchott, and Tema. The minister of finance will resume discussions with Côte d'Ivoire in the very near future.

${ }^{16}$ Ébémi means "where are you?" in Bambara. The system, designed in Mali, was supported by the Malian chamber of commerce and the national shipper and carrier boards. It will also be used by the police, gendarmerie, and Ministry of Transportation. According to information received, importers as well as chauffeurs are requesting to use the system.
} 
each trip) and the DGD plans for surveillance of the territory make this extension fully achievable.

\section{A new model of control of commercial operations to be implemented}

86. At this time, the majority of control operations continue to rely on customs bureaus. Despite the rigor applied and efforts made in verifications during customs clearance, the effectiveness of first line inspections have reached their limit. As shown in Table 6, the results of verification of value, origin, and tariff description have been modest.

Table 6. Customs disputes by type of violation, January-May2013 (en CFAF)

\begin{tabular}{lrrr}
\hline \multicolumn{1}{c}{ Type } & Duties compromised & \multicolumn{1}{c}{ Fines } & \multicolumn{1}{c}{ Amount of sale } \\
\hline Contraband & $61,017,742$ & $101,506,755$ & $59,669,343$ \\
Value & $248,420,495$ & $71,161,260$ & 0 \\
Cash & $50,142,716$ & $12,322,000$ & 0 \\
Diversion from destination & $33,167,019$ & $11,998,750$ & 0 \\
Other & $352,982,709$ & $240,380,274$ & 0 \\
Total & $\mathbf{7 4 5 , 7 3 0 , 6 8 1}$ & $\mathbf{4 3 7 , 3 6 9 , 0 3 9}$ & $\mathbf{5 9 , 6 6 9 , 3 4 3}$ \\
\hline
\end{tabular}

Source: DGD

87. To compensate for the bureaus' limitations, two offices were created in 2012 to strengthen control of commercial operations. ${ }^{17}$ They are the Value, Origin, and Tariff Division (DVOT) (a unit of the Directorate of Receipts and Verification Planning and Programs) and the Directorate of Post-clearance Inspections (DCAD). This is in line with previous recommendations. The functions and authorities of these offices should be defined, functional linkages should be established between them, and their capacities should be developed. In addition, DVOT capacities should be strengthened in these areas, which are critical for customs receipts.

88. The distribution of tasks involved in control of commercial operations should be organized as schematically indicated in Table 7. The number of controls should be rebalanced in favor of post-clearance inspections, and specialization should be developed in the two levels of control based on their comparative advantages. The added value of the DVOT lies in a strong capacity for research and analysis to better assist the two operational offices.

${ }^{17}$ Order No. 2012-148/P-RM of March 2, 2012 establishing the organizational framework of the Directorate General of Customs. 
Table 7. Proposed reorganization of customs control of commercial operations

\begin{tabular}{|c|c|c|}
\hline Unit & Current activities & Proposed activities \\
\hline $\begin{array}{l}\text { Customs bureau } \\
\text { (including specialized } \\
\text { bureaus) }\end{array}$ & $\begin{array}{l}\text { Performs most inspections. } \\
\text { Uses ASYCUDA selection to } \\
\text { conduct physical inspection } \\
\text { (red channel) or document } \\
\text { inspection (yellow channel). }\end{array}$ & $\begin{array}{l}\text { Focus on inspections for which the bureau has a comparative } \\
\text { advantage: } \\
\checkmark \quad \text { new operators, informal operators, high-risk operators } \\
\checkmark \quad \text { straightforward operations and irregularities (regardless of the } \\
\quad \text { operator) } \\
\checkmark \quad \text { verifications for which physical inspection is indispensable } \\
\quad \text { (quantity, nature, security, etc.). } \\
\text { Document findings and results (positive or negative) for post- } \\
\text { clearance use. } \\
\text { Report suspected irregularities that cannot be verified in immediate } \\
\text { inspection. } \\
\text { Reduced number of inspections. }\end{array}$ \\
\hline $\begin{array}{l}\text { Value, Origin, and } \\
\text { Tariff Division }\end{array}$ & & $\begin{array}{l}\text { - } \quad \text { Center of expertise - in-depth knowledge of rules. } \\
\text { - } \quad \text { Onesearch and analysis office (particularly as to prices). } \\
\text { or on request). } \\
\text { - Support in post-clearance inspection for complex cases. }\end{array}$ \\
\hline $\begin{array}{l}\text { Directorate of Post- } \\
\text { clearance Inspections }\end{array}$ & $\begin{array}{l}\text { Plays a limited role in customs } \\
\text { inspections }\end{array}$ & $\begin{array}{l}\text { Inspections covering roughly } 70 \text { percent of declared values - via } \\
\text { cyclical, comprehensive audit of major operators. } \\
\text { Extension of positive first line inspections (via deferred inspection) } \\
\text { and actions taken in response to reports of suspected irregularities. } \\
\text { - Inspection plans specific to exemptions. } \\
\text { - Increased number of inspections. }\end{array}$ \\
\hline
\end{tabular}

\section{This new organization represents a potential increase in receipts and facilitation} superior to the traditional organization. The second line is the only unit capable of conducting thorough inspections covering a large share of the traffic. Fewer but targeted first line inspections are, however, indispensable to facilitation (cf. Chapter III).

\section{Measures specifically related to value, origin, and tariff description}

90. Control of value presents difficulties. For roughly 55 percent of imports, the bureaus can use the certifications of value issued by the inspection company BIVAC to verify the declared value. For the rest, they must follow the rules provided by article VII of the General Agreement on Trade and Tariffs (GATT), given the lack of reliable tools. Several administrative [problems] persist. The DVOT should become a legitimate research office that continually collects information on product values in order to provide information to the bureaus to detect the most obvious anomalies (the others can be addressed following clearance). This effort should focus priorities on revenue-generating products.

\section{Goods declared to be of WAEMU origin and receiving preferential tariff treatment} represents close to one-fourth of Mali's imports. Verification of origin should therefore be intensified. While the bureaus' verifications are based on anomalies observed in certificate, wrapping, and merchandise, the DVOT's work should focus on analyzing commercial traffic to detect patterns of fraud, which are generally complex, to be addressed through post-clearance inspection (this analysis will also serve in risk management for the verifications performed by 
the bureaus). In addition, a mechanism should be established to interrogate WAEMU country customs administrations and cooperate with them. This is consistent with WAEMU legislation.

92. Certain goods obtained after processing in coastal countries are accompanied by certificates of preferential origin, although the common external tariff (CET) does not appear to have been applied to the input. The DGD should question the authority that issued the certification and, depending on the response and applicable community provisions, collect duties or bring the dispute before the WAEMU Commission.

\section{Regarding the tariff description of goods, three measures appear to be needed:}

$\checkmark \quad$ The DVOT should conduct periodic studies of the use of different tariff positions to detect anomalies;

$\checkmark \quad$ It would be advisable to issue opinions on the classification of goods. This approach has several advantages: predictability for the importer, harmonization of practices between bureaus, and reliability of the classification used by specialists in the area. It is recommended that opinions be issued at the operators' request ([see] advance decisions in Chapter III) and at the initiative of the customs offices.

$\checkmark \quad$ The use of laboratory analyses is indispensable for certain products to determine the tariff classification. Because laboratory analyses are expensive, the DGD should negotiate a partnership with a public or private laboratory in Mali.

\section{Conduct of post-clearance inspections}

\section{The organization of inspections is relevant and covers the different types of} inspections to be performed, including a section dedicated to monitoring exemptions, which have a considerable impact on receipts (cf. Annex 4). The offices have incorporated the methodology discussed during the March 2013 AFRITAC seminar. However, as for the other specialized offices, significant needs for specific training remain (such as accounting and further development in technical customs matters).

95. One of the points to monitor in particular is the need for greater care in drafting the official findings in accordance with customs dispute provisions, and ensure that the factual and legal statements demonstrate the infraction. Secondly, the number of cases challenged by operators that are referred directly to the courts should be limited to the use of administrative appeal procedures (cf. Chapter III). Post-clearance controls should begin with an analysis of risks specific to the directorate. Deferred inspections should be clearly distinguished from inspection by the bureaus: it should not be limited to the re-examined each declaration but should include validation of a selected sample using documentation requested from the operator or external information. On-site inspections should be clearly delineated and of limited duration. 


\section{Inspection units}

96. The BIVAC company provides the following services: (1) pre-shipment inspection of goods in the country of departure; (2) opinions regarding value and tariff description; (3) joint operation of scanners with customs; and (4) securing and loading of imported petroleum products from supply depots.

97. Ultimately, the DVOT should be capable of providing opinions on value and tariff description to the customs bureaus, enabling it to take over the pre-inspection contract. However, acquiring the capacities needed will be a gradual process. External opinions should be phased out only as progress is made, and should be maintained for products or sectors that continue to present difficulties for the DVOT.

In light of the inspections currently conducted by the DGD, inspection of goods by a company in the country of departure no longer appears necessary except as regards the informal sector. International experience shows that these types of inspections, in addition to or instead of customs inspections, do not contribute to the efficiency or modernization of the customs administration. Accordingly, physical inspection prior to shipment could be abandoned (opinions on value and tariff description would continue but would no longer be tied to the pre-shipment inspection). At the same time, there are advantages to continued outsourcing of verifications by scanner and measures to secure petroleum products.

\section{Enforced collection}

98. The Malian customs offices determine the amount of duties and taxes payable, which are collected by the Treasury offices. According to information received from customs officials, it appears that the Treasury's role is limited to that of cashier. The customs offices validate and collect penalties (article 322 of the Customs Code). The actions to strengthen postclearance inspections and improve procedures will result in increased duties and fees to be collected outside the clearance process, and thus without the collateral represented by the goods and, in most cases, without the possible use of a bond. Regardless of the amounts at issue, it is essential that customs debt be effectively collected; otherwise, controls of receipts is no longer justified and the administration's credibility is compromised. It is therefore important that the enforced collection function be effectively exercised.

\section{The DGD appears to be better positioned to handle ex post collection of duties and} taxes. As a rule, the division of functions between the customs offices (validation) and Treasury offices (collection) should be applied in all cases. ${ }^{18}$ However, in light of the fact that the customs

\footnotetext{
18 FAD generally recommends that tax and customs administrations collect duties and taxes. In the present case, the mission was informed that the Treasury offices used ASYCUDA system for collection and no difficulties have arisen in reconciling amounts allocated and collected in the clearance process in general. There is therefore no need to alter this division of functions.
} 
offices are responsible for collecting penalties, is probably more efficient for them to be responsible for ex post collection of duties and taxes. It would be advisable to ensure that they have the appropriate legal authorities. Although the Customs Code provides for coercive measures, a more appropriate measure than the current provisions would be to provide the authority to retain goods being imported or exported by a debtor (other than goods for which the debt is owed) until the debt is fully paid. ${ }^{19}$

100. As the example of transit demonstrates, time limits should be established for each phase of ex post collection of duties and taxes. Customs regulations should establish: (1) a time limit (on the order of 10 days) from the determination of the irregularity to provide notice of the amount payable by the debtor, and (2) a second time limit commencing from that notice (on the order of 30 days) for the debtor to make payment. The amount of the debt should be recorded in the customs accounting system when the notice is given.

\section{Petroleum product imports}

101. Information provided on petroleum product imports, the largest source of receipts, shows that imports are satisfactorily controlled. ${ }^{20}$ It was suggested that the risk analysis division monitor changes in volumes released for consumption to detect possible substitution of products taxed at different rates, since control of the end use of products is in principle the responsibility of the customs offices.

\section{Gold exports}

102. The DGD does not receive copies of refinery reports for gold and therefore does not correct the value indicated in the export declaration after the fact. In contrast, controls of the quantities declared are operational. $^{21}$

\section{Recommendations}

- $\quad$ Extend the transit securing mechanism (regional T1, Ébémi, mobile brigades) to all corridors; be rigorous in collecting duties payable (see recommended measures).

- Implement the proposed new organization of inspections between the first and second lines.

\footnotetext{
${ }^{19}$ This provision exists, for example, in Canadian customs legislation (cf. article 97.25 of the Canadian customs law, reproduced in Annex 5 of this report).

${ }^{20}$ Reference to the taxable base reported by BIVAC at removal from the foreign warehouse, simplification provided by disregarding inventory shrinkage, use of volumetric meters at release for consumption, and maintenance of customs control of certain exempt products such as aviation fuel.

21 Weighing in the presence of three administrations (customs, geology, and police) and the company.
} 
- $\quad$ Develop DVOT specialization in research and analysis to support the customs bureaus and operational directorates; gradually redefine the scope of services provided by the inspection company as the DVOT acquires new capacities.

- Verify WAEMU certificates of origin more systematically, in cooperation with the issuing authority, and take the authorized actions.

- $\quad$ Continue to professionalize the DCAD.

- $\quad$ Establish an office responsible for enforced collection of customs debt arising outside the clearance process, and propose any necessary modification of legal authorities.

- $\quad$ Closely monitored the variations in the volumes of petroleum products released for consumption, and obtain gold refinery reports to facilitate any correction in the values declared.

\section{B. Risk analysis and fraud prevention}

\section{Resumption of the automated risk analysis project}

103. In 2007, the DGD embarked on a project supported by AFRITAC West to establish an automated risk analysis capability for use in programming audits. AFRITAC conducted eight expert visits during the period ending November 2011. After the last visit, a transitional system was in operation. The events of March 2012 interrupted the project thereafter, and the transitional system has remained in place.

104. The immediate priority to restart the project is to ensure that all customs office findings resulting from inspections are captured in real time. In order for the risk analysis application to utilize this information, the results of inspections must be presented in the form of data. The DGD has designed a dispute form (CX form) for this purpose, but several actions are needed:

$\checkmark \quad$ The CX form is manual. In order to make the information available the same day and limit the need for human intervention, it should be incorporated into the ASYCUDA system and the data should be input immediately after the inspection;

$\checkmark \quad$ For purposes of risk analysis, both negative and positive results should be recorded;

$\checkmark \quad$ Reports should be prepared for all types of inspections by all offices;

$\checkmark \quad$ The application to which inspection data is input should immediately transfer the data to a centralized database that is continually updated.

105. The AFRITAC technical assistance, which is expected to resume in fall 2013, will include a re-examination of the CS form with the DGD and automation of the form. In order for 
this effort to be successful, the application should be designed so that the close of the inspection process requires The input of inspection data.

\section{Information, analyses, and studies to support inspections}

106. The findings of past inspections will facilitate the identification of known risks as well as potential risks. The risk information and analysis division should therefore conduct the following actions:

a) Investigate external information through advisors or in cooperation with other national and foreign administrations. The information obtained should be compiled in a national fraud database.

b) Analyze the information obtained for immediate action or the programming of inspections.

c) Establish operator profiles.

d) Conduct sector studies or studies of trends in trade flows.

107. In regard to clearance, the conclusions of analyses and studies should be converted into selection criteria in the automated risk analysis system.

\section{Scanner}

108. Because the DGD has only four scanners, it locates them in the customs offices located at the intersection of certain routes so as to inspect the maximum volume of goods using the scanner. The customs declarations are later filed at the destination bureaus, but it is not possible to x-ray the loads in view of the information declared in detail. The purchase of additional scanners is not suggested to address this difficulty, given the volume of merchandise involved and the use that can be made of a scanner. Instead, the mission recommends that: (1) if fraud is detected using the scanner, the bureau where the scanner is located should immediately prepare a report and conduct an inspection, and (2) mere suspicions of fraud should result in a warning in ASYCUDA at the time of the declaration, resulting in a red channel. However, the interpretation of images should be improved so as to limit the number of false warnings and declarations processed through the red channel.

\section{Planning and coordination of fraud prevention interventions}

109. The DGD has strong capacities in the area of fraud control and prevention. The Directorate of Customs Intelligence and Investigations (DRED) has a staff of 122, including the special fraud and transnational crimes brigade, which has deployed 12 bases pending the establishment of 63 advanced bases provided in the new customs map. The regional brigades are operational, as are the brigades piloted by the BCT for transit surveillance and the joint (DGDDGI) financial and economic intelligence and investigations committee. The recently created DCAD already has a staff of 26 . 


\section{In addition to specialized training for personnel of all these units, the main} challenge will be to deploy the units in a coherent and organized manner, avoiding overlapping areas of responsibility and harassment of users. Several measures will be important in meeting this challenge:

$\checkmark \quad$ A national anti-fraud plan should be prepared. It should be based on the major risks and priorities identified and cover all types of anti-fraud interventions.

$\checkmark \quad$ In implementing the plan, make use of an intervention programming application (annual inspection programs and targeted investigations (to avoid simultaneous intervention by several offices as to the same subject or operator.

$\checkmark \quad$ The surveillance units' interventions should be reported to an intervention coordination center (CCI) which should operate on a continual basis and be located within the fraud, transnational crime, and terrorism division.

$\checkmark \quad$ It is important to make a clear distinction, in terms of organization and methods, between verifying the compliance of commercial operations and conducting activities to combat criminal fraud. This will help ensure that the customs administration does not appear to be an exclusively deterrent force.

$\checkmark \quad$ Teamwork by the units is indispensable. To develop and maintain teamwork, the unit chief should ensure that all personnel who contribute information or collaborate in another unit's case receive due recognition. For the DGD as a whole, the director of the DRED should identify the ways and means to develop a culture of teamwork.

\section{Administrative entities}

\section{The organization of the DGD offices in general is coherent and efficient. Several} adaptations would be advisable to further improve the structure. In regard to the DRED research and interventions division, the research function belongs to the intelligence area, while the intervention function is associated with criminal investigations. It would be more relevant to remove the division from the organization chart, rename the "data exploitation" section as the "research" section and attach it to the information and risk analysis division, and to integrate the interventions section into the transnational crime and terrorism division. Finally, the CCI mentioned above should be created within that division.

112. The section in charge of deferred inspections by bureaus should focus on verification of the presence of documents to be attached to declarations processed through the green channel ${ }^{22}$ and on compilation of the paper declarations collected by the deferred inspections division's commercial documents collection section.

22 The actual deferred inspections are conducted by the DCAD deferred inspection division. 


\section{Recommendations}

- $\quad$ Reinstate the automated risk analysis project, beginning with automation of the CX form.

- $\quad$ Conduct the investigations, analyses, and studies needed to improve the automated risk analysis database (first line) and input data to the national fraud database (for the other offices).

- Incorporate suspicions of irregularities detected by means of the scanner as warnings in the ASYCUDA system.

- $\quad$ Coordinate anti-fraud efforts through a national plan, an application to rate inspections and investigations, and a center to coordinate interventions in the territory.

- $\quad$ Simplify the organizational structure of the DRED and avoid duplication by the deferred inspections bureaus.

\section{Trade facilitation and partnership}

\section{The DGD is aware that it should contribute to the government objective of} improving the business climate to support economic growth. It recently created a Directorate of Facilitation and Partnership with Business (DFPE). The immediate challenge is to effectively undertake this mission, and in particular to define the priorities for the directorate's actions. The following parameters should be used to guide the choice of priorities: (1) develop a thorough understanding of operators' concerns and compile an inventory of the specific requirements of Malian businesses; (2) explore channels of cooperation with the private sector to achieve the government's objectives; (3) develop shared responsibilities in order to reduce fraud and improve security; and (4) and develop a business investment that is internationally recognized as favorable.

\section{The DFPE should be tasked with the cross-cutting mission of initiating and} overseeing the application and results of the DGD action plan on trade facilitation, which will involve several customs offices. During the mission, several needs were identified that should be incorporated into this action plan.

115. Framework for consultation with operators. The partnership approach should begin with the formalization of a consultative framework with two main components: (1) meetings between high-level representatives of the private sector and the administration to discuss and validate reform plans, particularly in connection with the preparation of legislative changes and the DGD trade facilitation action plan; ${ }^{23}$ (2) operational meetings to resolve practical problems and monitor implementation of the action plan.

\footnotetext{
${ }^{23}$ According to information received, a colloquium was organized in 2010 on "Improving performance through partnership," but it did not lead to the establishment of a formal framework for such exchanges.
} 
116. Simplification of procedures. Procedural simplifications warrent close review in the context indicated above. However, the mission noted the following simplifications that could be implemented without delay:

$\checkmark$ Use the T1 transit document instead of the manifest, with customs officials verifying that all $\mathrm{T} 1$ documents are sufficiently explicit.

$\checkmark$ Container shipments sealed at the time of export whose seals are intact should be cleared at domicile. If the inspection company attached the seals, the container should not be required to be x-rayed.

$\checkmark$ For direct removal (D24), two procedures should be distinguished. Both should be completely automated, and penalties should be established if procedures are not completed by the established deadline (a very frequent occurrence): (1) urgent operations (e.g., perishables, urgent spare parts); and (2) delay in receiving documents (e.g., exemption authorization not available). In the former case, the declaration will be minimal; in the latter case, a full declaration will be required except for any missing document(s) allowed to be submitted at a later date.

117. Expediting customs clearance. The customs bureaus appear to meet the current objective of clearing within 72 hours, but this is still slow in relation to international standards. Customs offices should initiate the action provided in the 2013 action plan (reduce clearance times to 24 hours by 2015) and identify the factors of delay and measure times using ASYCUDA. Advance declarations should be promoted extensively, making use of the time in transit from ports. The DGPC has used advance declarations in the past in order to collect revenue in advance, which is not a good practice. It is suggested that the advance declaration be validated at the time the merchandise arrives.

118. Development of economic customs procedures. Customs procedures permitting the fabrication or processing of products for which duties and taxes have been suspended are underutilized. Forty-seven "industrial warehouses" are managed by the DGD, yet there are over 500 industrial businesses in the Bamako region alone that import. The DFPE should review the reasons for this situation and propose corrective measures. It is possible that the regulations are not sufficiently attractive, are not well known, or that the current customs practices are still too restrictive.

119. Preferred operators program. It is in the customs offices' interest to develop segmentation of operators, and in particular to offer benefits to operators who follow the rules and commit to continuing to do so. When major operators can access the program, a large share of customs receipts are thereby secured (50 importers in Mali accounted for 37 percent of customs receipts in 2012). A pilot program should be initiated by identifying candidates in the following sample: the 10 largest importers in terms of value, the 10 largest in terms of duties and taxes, the 10 largest in terms of number of declarations, and the 10 importers most compliant with customs rules. This will exclude candidate firms (or their executives) that have committed 
serious infractions, firms with outstanding debt, firms that repeatedly violate customs or tax rules or are suspected of infractions, and new importers. ${ }^{24}$

120. Right of appeal. The GATT Accords and the revised Kyoto Convention ${ }^{25}$ require the right to appeal customs administration decisions before an independent body before initiating legal proceedings. Article 27 of the Customs Code established the Customs Tariff Commission (Comité Supérieur du Tarif des Douanes, CSTD), whose authority is limited to disputes regarding value, tariff description, and origin "at the time goods are inspected" (article 104). The right of appeal should be expanded to include post-clearance inspections.

121. The mission noted that an initial right of internal appeal to the director general of customs exists for all customs office decisions. ${ }^{26}$ However, this right is not formally provided in the Customs Code. A new provision should be added to formal establish this right (cf. Annex 5).

122. User services. The DFPE should tailor the services provided to users to the extent possible, at its initiative and on request. The services should include advance decisions, particularly regarding tariff classification; the organization of thematic conferences; and periodic outreach to new importers and exporters regarding their obligations and the services available to them. In keeping with the communication component of the strategic plan, is important to ensure that all customs rules are published on the Internet.

\section{Recommendations}

- $\quad$ Establish a consultative framework with operators to discuss planned reforms (first component) and resolve practical problems (second component).

- $\quad$ Develop an action plan for the DFPE including, inter alia: (i) the streamlined procedures recommended (elimination of the customs manifest, sealed containers cleared at domicile, automation of D24); (ii) gradual reduction of customs clearance times; (iii) promotion of economic customs procedures and adjustment of procedures as necessary; (iv) a pilot preferred operators program; (v) a formal framework for an extension of the right of appeal; and (vi) tailored assistance to operators.

\footnotetext{
24 The DGD could ultimately aim to grant Authorized Economic Operator (OEA) status completely online in accordance with World Customs Organization (WCO) standards.

${ }^{25}$ Chapter 10, Standard 10.5 .

${ }^{26}$ Consistent with Chapter 10, Standard 10.4 of the revised Kyoto Convention.
} 


\section{Automation}

\section{System security}

123. The DGD has selected the ASYCUDA system developed by UNCTAD. Nearly all of the customs bureaus were automated and interconnected in early 2012. During the events of March 2012, the computer hardware at the directorate general and numerous bureaus was destroyed, including the central server and cables. Most of the data was lost. After quickly resuming manual operations, the customs offices currently work with a backup server, which is vulnerable and cannot serve as a long-term option.

124. As the DGD has emphasized, installing an adequate server and securing the system and data is an urgent priority. During the mission, the French Embassy, a delegation from the French customs administration, and the DGD came to agreement on a plan to acquire and install a customs data center. ${ }^{27}$ Financing will be provided by the French authorities, and the DGD will implement the data center with technical support from the French customs administration. Project completion is scheduled for January 2014.

\section{Migration to SYDONIA World - additional functionality required}

125. The customs services currently use the ASYCUDA++ version. Before the events of March 2012, the DGD had prepared for migration to the ASYCUDA World version, and payment had even been made to UNCTAD. The project is expected to be quickly resumed. UNCTAD is expected to conduct an initial visit in the near future (planned for November 2013) to update the project if necessary and establish a timetable. The World version could be completely operational by end-2014.

126. SYDONIA World should bring real advances in regard to procedures. To this end, it is important to: (1) rationalize and simplify procedures to the extent possible in preparation for the migration; and (2) anticipate all functionalities required, whether as integral parts of the ASYCUDA system or associated applications. This report contains recommendations in both areas. Box 4 lists a number of functionalities that could provide added value in the short term.

\footnotetext{
${ }^{27}$ A data processing center where electronic equipment, servers, storage systems, telecommunications, and a management system are located.
} 


\section{Box 4. Priority customs information processing functionalities}

- Connection of Malian customs officers at ports;

- Advance declarations;

- Remote input of declarations by operators;

- Automated risk analysis application;

- Automation of emergency removals and declarations with missing documents (D24);

- For suspended duties and taxes: allocation of guarantees, automated clearing, and support for payment of duties and taxes;

- Files: national fraud database, indicative values, notice of tariff classification, dispute matters;

- Inspection and investigation rating application;

- Input of results of all inspections in the system (automated CX file);

- Warning system and notification of operations to be inspected by another customs office;

- Decision support: management table, composite indicators;

- Personnel file (PEDONIA).

\section{Electronic documents and one-stop window}

127. Despite the use of ASYCUDA, the customs services and operators continue to work in a paper environment. Operations are automated but not yet paperless. The DGD notes that ASYCUDA World provides greater support for implementation of a one-stop window for international trade. The first step for this type of one-stop window is to convert the customs declaration and associated documents to paper form. Once the basic applications are operational, as indicated above, the DGD should assume the lead role in an interagency project to adopt paperless documents and electronic information exchange in the context of a one-stop window.

\section{Information technology staff}

128. The information technology staff allocated to the DGD includes only four engineers (including ministry support), which is clearly insufficient in regard to projects and the importance IT has assumed. Moreover, they also lack the training required in the context of the migration, particularly training in Java. Personnel should be hired and trained as soon as possible to ensure the success of IT projects.

\section{Recommendations}

- $\quad$ Continue the data center installation project supported by the French authorities.

- $\quad$ Use the migration to the ASYCUDA World as an opportunity to rationalize and simplify procedures and develop the functionalities that will bring improvements in the short term.

- In the medium term, undertake the project to convert the documents required for clearance to paperless form and implement a one-stop window for international trade.

- $\quad$ Hire and train a sufficient number of IT staff. 


\section{E. Resource management and supervision of services}

\section{Human resource management}

129. The strategic plan represents a relevant response to the personnel management gaps previously identified. Pillar 3 of the plan covers the following issues: (1) the need for a human resource management plan; (2) the redeployment of personnel; (3) the tightening of rules governing external recruiting; (4) quality initial and continuing training; and (5) strengthening of professional ethics.

130. Significant progress has already been made. The texts concerning the special status of customs officials and career plans were adopted, ${ }^{28}$ strengthening in particular respect for reporting relationships and personnel motivation. The training center was restructured, instructors were hired, and the unit was placed under the supervision of the deputy director general. Numerous training activities have already been conducted, in addition to the initial training, which is operational. ${ }^{29}$ By way of example, 500 customs employees have received training in customs surveillance. The preparation of position descriptions is in progress for all DGD personnel. Internal control is now in place (cf. below). A code of ethics was adopted by administrative order, ${ }^{30}$ demonstrating the importance attached to this issue.

131. The personnel file and profiles should be recreated in the short term, since the PEDONIA file was lost during the events of 2012. The file is used in all personnel management functions, including assignments, training, redeployments, and recruitment planning.

132. Hiring modalities should be revised. The unexpected assignment of numerous civil servants to the DGD was observed. This practice was interrupted, but it is essential that it be ended definitively. The Ministry of Civil Service should effectively consult the DGD. As the first step, the DGD should present its requirements in terms of the number and category of staff required. ${ }^{31}$ It should then propose the hiring of specific staff members with specialized, noncustoms expertise according to requirements previously identified (for example, accountants and IT staff). This approach will contribute to the sustainable modernization of the customs administration.

${ }^{28}$ Orders 2013-117/P-RM and 2013-121/P-RM of January 31, 2013, respectively.

${ }^{29}$ Category A managers receive their initial customs training at ENA. Category B managers complete one year of professional customs training, including four months of military training, two months of training in the use of information technology, and six months of training in customs techniques.

${ }^{30}$ Order no. 2013-122/P-RM of January 31, 2013.

${ }^{31}$ Currently, category $\mathrm{A}$ is overrepresented, while the surveillance function, which should be developed, requires category $\mathrm{C}$ staff. 
133. The geographic and functional redeployment of personnel is essential. The following principles should be applied in the context of a modern customs administration: (1) increased specialization of all personnel currently assigned to headquarters offices; (2) adaptation of bureau staff in regard to automation and facilitation; and (3) broad use of staff in customs surveillance of the territory and efforts to control smuggling and illegal trafficking. DGD managers have already prepared a new "customs map" in line with these principles, ${ }^{32}$ but implementation was delayed by the events of 2012-2013. Insecurity in the Northern part of the country resulted in the temporary relocation of customs agents to bureaus in the South. They should be returned to the North and a national redeployment should be launched as provided by the new customs map.

134. The training program should be continued but accompanied by a sound policy for stabilizing personnel in their positions. The continuation of projects to improve initial and ongoing training is essential. However, the investment in training and experience should be protected to the extent possible by keeping specialists in their jobs. For these types of positions, the DGD should give preference to four-year assignments.

\section{Supervision of staff}

135. The performance contract between the minister and the director general provided by the plan, on which an agreement in principle has been reached, is an excellent initiative. It will be important, however, to extend the performance evaluation beyond results in terms of receipts collected, both to provide incentives to conduct all customs missions effectively and to ensure that receipts are collected in accordance with all national and international rules. ${ }^{33}$

\section{Control of the performance of tasks and professional ethics should continue to be} strengthened under the enterprise approach. The strength of this approach lies in the use of two coordinated levels of control, by the supervisor and by the BCI. The planning of controls, the control procedures manual, and the written report of the supervisor's control are notable innovations. Several observations were made during the mission:

$\checkmark \quad$ Control by the BCI should cover the use of the IT system and data. Misappropriation and fraudulent use have occurred in this area in numerous customs administrations.

$\checkmark \quad$ Once the procedures for input by supervisor and employee have been completed, it is the action effectively taken on the BCI recommendations that will confirm the success or weaknesses of the internal control approach: according to the case in question,

\footnotetext{
32 The customs map includes, notably, the 63 advance bases mentioned in Chapter II of this section.

${ }^{33}$ It has been observed that in developing countries, customs revenue is often collected with insufficient attention to commitments vis-à-vis the World Trade Organization and compliance with regional integration agreements
} 
modification of organization or procedures, imposition of disciplinary and/or legal sanctions, including recovery of misappropriated funds if applicable.

$\checkmark \quad$ A campaign should be organized to communicate and explain to each staff member in detail the obligations established by the code of ethics.

The DGD, as the entity responsible for accrediting customs commissioners, should institute control procedures for the profession (which would logically come under the authority of the directors of regulations, litigation, and international relations).

137. Management tables with indicators associated with the activities of each directorate should be developed and used in the context of the performance contract and contracts based on agreed objectives and for internal control. They should be generated automatically by ASYCUDA (to the extent possible) or by other systems. With respect to the actual execution of tasks, all of the automated ASYCUDA World reports should be understood and utilized.

\section{Budget and resource management}

138. A comprehensive analysis of investment requirements for the coming years should be conducted and a single investment plan should be prepared. In addition to the government budget allocation (CFAF 720.6 billion in 2013), the DGD has a specific budget of CFAF 5 billion for rebuilding and rehabilitating offices, as well as other sources of financing such as the Government Action Plan to Improve and Modernize Public Financial Management (PAGAMGFP) and the information technology fee. The expected return on investments - additional revenue and the impacts of strengthened anti-fraud and facilitation efforts - should guide priorities of the single investment plan suggested. According to this principle, the priorities should include: information technology, vehicles for offices required to conduct inspections at operator premises or within the territory, the selective establishment or reestablishment of customs offices in certain priority areas of activity, and the expansion of Ébémi.

\section{Recommendations}

- In re creating the personnel file, institute a forward approach to personnel management, including programming of training and recruiting.

- $\quad$ Negotiate (at the ministry level) an agreement with the Ministry of Civil Service whereby the DGD identifies its specific hiring needs in terms of both category and specialization.

- Launch a national geographic and functional redeployment plan; limit the rotation of specialized personnel to optimize the training provided.

- Institute the performance contract and use it as a tool for continued improvement in the performance of all functions, without limiting it to collection results. 
- Continue strengthening internal control in accordance with the principles identified, taking action on the proposed corrective measures and sanctions, and incorporating control of the use of the IT system and data.

- Implement a program designed to ensure that all personnel have full knowledge of the obligations established by the code of ethics.

- $\quad$ Select the customs performance indicators and take steps to ensure that ASYCUDA and other systems generate management tables without need of manual intervention.

- $\quad$ Prioritize investment needs in the form of a single plan, considering above all the expected return on investment.

\section{ESTIMATION AND MONITORING OF TAX EXPENDITURE}

139. Exemptions are granted: (1) through sector provisions (mining, petroleum and investment codes, free trade zone, real property code, tourism code, microfinance code, artisanal trades code) and specific conventions; (2) in the context of external or NGO-financed development operations; (3) in connection with diplomatic privileges; and (4) in generally applicable laws (General Tax Code).

140. Tax exemptions are considered a major form of incentive in Mali, and as such they are used extensively. Paradoxically, despite the substantial tax losses to the Malian government, the tax expenditure represented by these exemptions was not evaluated in accordance with international standards until recent years: estimates of foregone tax receipts for imports were prepared using customs statistics (cf. recent data in Annex 4) and partial information for taxation maintained by the DGI. These types of estimates of lost tax revenue could not serve as a management tool for Mali's fiscal policy and public expenditure: ${ }^{34}$ at the very most, the estimates provided an initial indication of the size of the tax losses following the implementation of exemptions.

141. The November 2011 FAD mission had identified the need to evaluate tax expenditure. The central objective of such an evaluation is to provide the authorities with the information needed to optimize the use of the various incentives (notably, tax exemptions versus subsidies). It also provides the information required to identify the effect of exemptions on changes in the different categories of tax receipts.

142. Based on experiences in Morocco and Senegal, the 2011 mission had presented the essential conditions to be met to evaluate tax expenditure in Mali in accordance with

\footnotetext{
${ }^{34}$ An analysis of tax expenditure and its role is provided in Godbout L. L'intervention gouvernementale par la politique fiscale, Le rôle des dépenses fiscales, Etude comparée: Canada, Etats-Unis. [Government Intervention through Tax Policy, the Role of Tax Expenditure. Comparative Study: Canada, United States]. Economica, 2006.
} 
international standards. A summary action plan (see Annex 5 of the 2011 FAD report) had been presented to provide an initial evaluation of tax expenditure to accompany the 2013 budget law.

143. As recommended by the 2011 mission, the authorities adopted the practice of presenting an annual evaluation of tax expenditure together with the proposed budget law.

144. The Tax Policy Unit (CPF), composed of three persons including an econometrician, collected data at the DGI and DGD on loss of revenue following the adoption of various exemptions and similar measures. A table summarizing loss of revenue by type of tax was prepared for 2012, while the data for first quarter 2013 were centralized. In 2012, tax expenditure represented 4.4 percent of GDP (Table 8). Furthermore, in May 2013, the CPF produced a "memorandum on tax expenditure" discussing the methodology used.

Table 8. Tax expenditure in 2012

(CFAF millions)

\begin{tabular}{|l|c|}
\hline & 2012 \\
\hline Tax expenditure under the CGI & 332.7 \\
\hline Tax expenditure under the Investment Code & 108657.3 \\
\hline Tax expenditure under the Mining Code & no data \\
\hline Tax expenditure under ministerial orders & 3.1 \\
\hline DGI tax expenditure & $112,084.6$ \\
\hline DGD tax expenditure & $116,696.4$ \\
\hline Total tax expenditure & $228,781.0$ \\
\hline
\end{tabular}

Source: $\mathrm{CPF}$

145. The adoption of the practice of presenting an evaluation of tax expenditure together with the budget law ${ }^{35}$ accomplished an initial step toward addressing the issues of the method and collection of information on the tax expenditure generated by exemptions. The estimates prepared for 2012 confirm the substantial amount of tax expenditure and the need to take the necessary actions to provide Mali with an evaluation of tax expenditure conforming to good international practices.

\section{A. Difficulties encountered}

146. An ambiguous reference tax system. The above-referenced memorandum of the CPF regarding tax expenditure (May 2013) refers to both the general tax and customs code and the sector incentives without indicating which system serves as the reference.

147. The choices relating to the reference tax system appear implicit and may be deduced in part from the CPF evaluation of tax expenditure. Tax expenditure arising from VAT exemptions

\footnotetext{
35 The May 2013 Letter of Intent concluded by the authorities with the IMF includes this principle.
} 
in 2012 is negligible. Yet under article 195 of the CGI, amended by the 2012 budget law, a large portion of the tax base is excluded from application of VAT through particularly substantial exemptions of consumption (particularly basic consumption and consumption associated with education and health). These exemptions produce a substantial loss of VAT receipts that should be addressed, although implicitly, VAT exemptions under article 195 are considered part of the reference tax system. This choice is in contradiction with the DGI 2012 inventory of tax exemptions, which classifies VAT exemptions under CGI article 195 as exceptional arrangements.

148. Because it considers VAT exemptions as components of the reference tax system, the CPF evaluation of tax expenditure does not estimate the amount - or therefore the impact - of the tax expenditure attributable to this category of exemptions. Accordingly, the quantitative data provided by the evaluation of tax expenditure cannot serve as the basis of a potential policy to reduce - or alternatively extend - VAT exemptions provided by generally applicable laws. This choice also makes it impossible to identify the determinants of the VAT efficiency ratio, since the exclusion of substantial consumption from VAT under general tax laws is one of the key reasons for reduced VAT efficiency in Mali.

149. The absence of an explicit, detailed definition of the reference tax system therefore affects the scope and quality of analysis that can be conducted based on the evaluation of tax expenditure. For example, considering VAT exemptions for health-related spending as part of the reference tax system makes it impossible to compare a health policy that relies on exemptions to one that makes greater use of subsidies.

150. The explicit, detailed definition of a reference tax system is the next step to be completed to evaluate tax expenditure in Mali. Experience in several countries (Haiti, Morocco, Senegal ${ }^{36}$ ) demonstrates that in light of the crucial importance of the choice of reference tax system, the principal aspects concerning its definition require thorough, high-level reflection in order to provide a relevant response to the authorities' information requirements.

151. In the three countries referenced above, reflection concerning the reference tax system was conducted in the context of a national workshop whose participants included all the administrations expected to contribute to or make use of the evaluation of tax expenditure. The work of the national workshops was greatly facilitated by taking into consideration other countries' experiences in evaluating their tax expenditure. The manual published by the Inter-

\footnotetext{
36 The mission provided the CPF with information on experiences in Haiti, Morocco, and Senegal, noting that the evaluation of tax expenditure in Morocco, which is attached to each annual budget law, is available on the website of the Moroccan tax authority [www.tax.gov.ma].
} 
American Center of Tax Administrations (CIAT) ${ }^{37}$ may be useful in providing the necessary conceptual definitions.

152. Insufficient inventory of measures establishing exceptions to the reference tax system. In the absence of a detailed, explicit definition of the reference tax regime utilized, it was not possible for the CPF to prepare a detailed inventory of exceptional tax measures and go beyond the inventories ${ }^{38}$ already prepared by the DGI. During working sessions with DGI staff, the mission indicated that the inventory should be as exhaustive as possible and include all exemptions, including exemptions pursuant to conventions or specific provisions. For the recent past, it should include the exemptions provided in the context of operations to restore security and all other measures, including "cyclical" measures.

153. Evaluation methods relying solely on unadjusted tax or customs statistics. Certain large tax expenditure arising from certain exemptions cannot be evaluated by simply aggregating data maintained by the customs or tax administrations, including certain particularly large tax expenditures arising from VAT exemptions (notably, the exemption provided by CGI article 195). A joint effort with the National Statistics Institute, utilizing macroeconomic estimates of the tax bases to which the exemptions apply, will be needed to evaluate the tax expenditure generated by these exemptions.

154. Lack of credibility of tax expenditure estimates. To succeed in exerting an operational impact on the authorities (government, legislature) or civil society and serve as a genuine decision making tool, it is important that the evaluation of total tax expenditure for a fiscal year appear credible, and in particular that it conform to international standards.

155. In practice, to avoid excessively complex calculations and delays that would preclude simultaneous presentation with the budget law, evaluators of tax expenditure admittedly ignore most interactions between taxes. For example, the increased tax revenue from an income tax that should result in an exemption from another direct tax - e.g., a business license tax or property tax - is not taken into consideration. Similarly, the effect of exemptions from indirect taxes (particularly tariffs) on the proceeds of income taxes is generally not considered.

156. However, this practice of simplification cannot be systematically extended without undermining the credibility of the evaluation. Thus, a loss of VAT revenue is recorded in Customs for the VAT exemptions relating to equipment imports. But if the equipment is acquired by operators subject to VAT, the VAT applied to the equipment becomes chargeable to VAT debits. Accordingly, a substantial portion of VAT exemptions on the equipment or

\footnotetext{
${ }^{37}$ Inter-American Center of Tax Administrations: Handbook of Best Practices on Tax Expenditure Measurements. An Iberoamerican Experience, Panama, 2011.

${ }^{38}$ DGI, Inventory of tax exemptions in Mali - Part I: Generally applicable provisions (CGI); and Part II, Exceptional provisions. October 12, 2012.
} 
intermediate consumption of operators subject to VAT recorded in Customs does not represent a definitive loss of revenue and should therefore be deducted from the amount of VAT exemptions recorded by the customs offices.

157. Lack of evaluation of exemptions' economic and social impact. The evaluations available for Mali are associated with incentive mechanisms (e.g., the Investment Code), the institutional origin of the exemptions (exemptions managed by the DGI or DGD), or, finally, the type of tax in question.

158. However, the foregone revenue is not broken down according to criteria required for economic and social analysis: there is no breakdown of loss by beneficiary sector (for example, mining, agricultural activities, education, health, infrastructure, housing, energy), by geographic area, or by beneficiary category (poor or non-poor population). This gap poses an obstacle to the analyses required to evaluate and quantify the economic and social impact of exemptions.

159. The main choices to understand the effects (allocation by sector, geographic area, or beneficiary category) will determine the capacity to provide a relevant response to the questions raised in defining the tax policy. This choice is therefore one of the aspects determined in the context of a national workshop.

160. Inability to make optimum use of tax and fiscal tools. A transparent, effective tax incentive policy relies on a consistent evaluation (Godbout, 2006) of government efforts in terms of budget expenditure (budget subsidies) and tax expenditure (exemptions). Accordingly, the evaluation of tax expenditure is part of an approach that facilitates rational arbitrage between tax expenditure and budget expenditure. Such arbitrage would require that the effects of exemptions and subsidies be analyzed using a common methodology: tax expenditure and public subsidies must be broken down according to the same nomenclature. ${ }^{39}$ A common nomenclature for tax expenditure and budget subsidies also facilitates a consolidated evaluation of all benefits (tax exemptions and subsidies) received by a single beneficiary category.

161. Lack of consistency over time. It is essential that the authorities be provided with evaluations of tax expenditure that support a correct understanding of changes over time. Such evaluations make it possible to conduct dynamic analyses, particularly to evaluate the efficiency of potential measures to reduce tax expenditure or, alternatively, to quantify the impact of the new exemptions on tax expenditure. ${ }^{40}$

\footnotetext{
${ }^{39}$ This type of harmonization of nomenclature is planned in Morocco.

${ }^{40}$ Once this stage is reached, analyses that are useful in evaluating tax policies can be conducted. The evolution of tax expenditure can serve as the basis for evaluating the impact of changes in the efficiency of tax administration. Such an evaluation was recently conducted for VAT [in Morocco] (cf. Communication to the national conference on tax policy, Skirat, April 2013).
} 
162. As demonstrated above, the essential methodological choices (for example, the reference tax situation utilized) largely affect the outcome of the evaluations - as do the modalities of evaluation, particularly where indirect, exhaustive evaluations based on statistics maintained in tax or customs administration databases are not possible. A change in evaluation method from one fiscal year to another is incompatible with a consistent measure of the evolution of tax expenditure over time. It is important, then, to use the same evaluation methods for a given source of tax expenditure from one year to the next. To ensure the consistency of evaluation methods, an updated, detailed compendium should be maintained of the evaluation methods utilized. The compendium would serve two purposes: ensuring consistency of evaluations over time and meeting any requests for information (authorities, legislature, civil society) concerning the evaluation methods utilized.

\section{Recommendations}

- $\quad$ Establish the objective of presenting an evaluation of tax expenditure conforming to best practices together with the proposed 2015 budget law, establish a steering committee dedicated to evaluating tax expenditure, and establish an action plan and timetable (see 2011 FAD report).

- Increase the resources of the team responsible for evaluating tax expenditure, especially for the first year of the evaluation.

- $\quad$ Organize a national workshop ahead of time to determine the essential methodological choices needed to evaluate tax expenditure in Mali, and make other developing countries' experiences in evaluating tax expenditure accessible ${ }^{41}$ to the workshop participants.

\footnotetext{
${ }^{41}$ A seminar on methods specifically addressed to West African countries would provide an opportunity to share experiences among countries that have evaluated their tax expenditure or initiated such an evaluation (Burkina Faso, Mali). It could also promote convergence in West African countries' choice of methodologies. The seminar should take account of the results of the July 11-13, 2012 regional seminar in Abidjan on evaluating tax expenditure, organized by WAEMU.
} 


\section{Annex 1}

\section{Implementation Status of Recommendations of the 2011 FAD Mission}

\begin{tabular}{|c|c|}
\hline Recommendation & Action taken \\
\hline \multicolumn{2}{|c|}{ Continued modernization of the DGI } \\
\hline $\begin{array}{l}\text { Evaluate the } 2009-2011 \text { strategic plan and prepare the } 2012-2014 \text { plan based on the } \\
\text { priorities identified by the mission and recommendations of this report. }\end{array}$ & $\begin{array}{l}\text { An action plan was prepared in the context of the } \\
\text { crisis for the period end-2012-2013. }\end{array}$ \\
\hline \multicolumn{2}{|l|}{ Elimination of VAT withholding } \\
\hline $\begin{array}{l}\text { Establish an action plan to prepare for the elimination of VAT withholding outsourced by } \\
\text { large businesses. The plan would include the following steps: (1) a communication } \\
\text { campaign targeting VAT taxpayers; (2) validation of information at businesses that } \\
\text { withhold VAT; and (3) measures to follow up with VAT nonfilers and collect } \\
\text { payments. }\end{array}$ & $\begin{array}{l}\text { VAT withholding at source by large businesses was } \\
\text { eliminated in January } 2012 \text {. } \\
\text { VAT withholding at source for public contracts, } \\
\text { implemented by the Treasury, was limited to } 40 \\
\text { percent of VAT payable in January } 2013 \text {, and } \\
\text { will be completely eliminated on January } 1 \text {, } \\
2014 \text {. }\end{array}$ \\
\hline Prepare the same action plan for elimination of VAT withholding on public contracts. & Completed. But reinforce support measures. \\
\hline \multicolumn{2}{|l|}{ Refund of VAT credits } \\
\hline $\begin{array}{l}\text { Extend the refund of VAT credits to investors and businesses that pay VAT at a reduced } \\
\text { rate. }\end{array}$ & Refund of VAT credits is extended to investors. \\
\hline $\begin{array}{l}\text { Revise the procedure for reviewing requests for refunds as well as the modalities of } \\
\text { payment in order to reduce the time required to issue refunds to between } 10 \text { and } 30 \\
\text { days according to the tax risk presented by the requesters. }\end{array}$ & $\begin{array}{l}\text { Completed. Measures were taken to secure an } \\
\text { effective refund (payment of a portion of gross } \\
\text { VAT from the BCEAO account and expedited } \\
\text { procedures). }\end{array}$ \\
\hline \multicolumn{2}{|l|}{ Improved segmentation } \\
\hline $\begin{array}{l}\text { Redefine the segments of the tax population to facilitate better monitoring of VAT } \\
\text { taxpayers and the system of taxation based on actual income. }\end{array}$ & To be done by January 1, 2014 \\
\hline $\begin{array}{l}\text { Strengthen and re-position the DME within the DGI and improve relations between the } \\
\text { DME and the CDIs. }\end{array}$ & To be done \\
\hline \multicolumn{2}{|l|}{ Redefine the roles of the DME and CDIs based on the following principles: } \\
\hline $\begin{array}{l}\text { The DME should be responsible for managing VAT taxpayers, including small } \\
\text { businesses that have the option to choose to pay VAT. }\end{array}$ & $\begin{array}{l}\text { The DME will be responsible for businesses with } \\
\text { turnover between the VAT threshold (CFAF } 50 \\
\text { million) and the turnover threshold for } \\
\text { businesses managed by the DGE (CFAF } 1 \\
\text { billion) beginning January } 1,2014 \text {. }\end{array}$ \\
\hline $\begin{array}{l}\text { The CDIs should have sole responsibility for small businesses and microenterprises } \\
\text { with turnover of less than CFAF } 50 \text { million (except those given the option of } \\
\text { choosing VAT). }\end{array}$ & To be done starting January 2014. \\
\hline \multicolumn{2}{|l|}{ Taxation of small taxpayers } \\
\hline $\begin{array}{l}\text { Apply the VAT threshold (CFAF } 50 \text { million) to all businesses regardless of the legal form } \\
\text { under which they operate, i.e., including legal entities. }\end{array}$ & Legal entities remain automatically subject to VAT. \\
\hline $\begin{array}{l}\text { For small businesses with turnover within the range of CFAF } 10 \text { (or 15) million - CFAF } \\
50 \text { million, replace the alternative minimum tax system with a system based on income } \\
\text { reported on a "cash basis." }\end{array}$ & $\begin{array}{l}\text { Under review, the taxation of small businesses will } \\
\text { be based on a simplified system of filing returns. }\end{array}$ \\
\hline $\begin{array}{l}\text { Establish a segment of microenterprises (e.g., microenterprises with turnover of less than } \\
\text { CFAF 10-15 million) and establish a flat tax applicable to them. }\end{array}$ & To be done \\
\hline $\begin{array}{l}\text { Eliminate the current distinction between the tax and accounting treatment of legal entities } \\
\text { and individuals, including for purposes of the VAT threshold. }\end{array}$ & To be done \\
\hline $\begin{array}{l}\text { Strengthen the research and validation office to enable it to develop targeted validation } \\
\text { programs to identify operators that abuse the tax systems for small businesses and } \\
\text { microenterprises. }\end{array}$ & $\begin{array}{l}\text { In progress. Creation of a ministerial committee to } \\
\text { strengthen tax research (see Chapter III-C) }\end{array}$ \\
\hline
\end{tabular}




\section{Development of research activities}

Refocus the activities of the research and investigation division on programming tax audits (a target of 20 percent of programming based on recommendations by research offices could be considered).

Establish a methodology for collection and use of tax-related information that promotes rapid processing (the older the information, the less useful it becomes) of the most useful information (information relating to operations beyond a certain threshold) that is enriched beforehand (the information is transmitted after reconciliation with data maintained by the operational offices).

Simplify businesses' obligations and reduce DGI workloads by: (1) eliminating notices of assessments for IBIC and corporate tax; (2) simplifying the RSI; and (3) modernizing collection procedures.

Strengthen the effectiveness of control through the following measures: (1) expand the use of ad hoc audits for VAT audits; (2) increase the number of dedicated tax audit staff; (3) team leaders (position to be created); (4) develop the SYGTAS tax audit module to implement effective monitoring of control, particularly collections.

Establish a plan to clear tax arrears, including: (1) classification of tax arrears by category; (2) analysis of the recoverability of all tax arrears; and (3) selection of the procedures to be followed based on the category of tax liability (giving preference to the largest liabilities with the best chances of recovery).

In the context of assistance provided under the new Canadian development agency project, PAMORI 2, strengthen the IT tool through the adaptation of infrastructure supporting SYGTAS, particularly the network, equipment, and electronic data transmittal for the automated offices.

Continue development of the program to educate businesses by (1) targeting information actions according to taxpayer size, (2) providing specialized training to staff assigned to this mission, and (3) developing a program of visits to new businesses.

\section{Estimating tax expenditure}

Adopt the principle of evaluating tax expenditure in accordance with best practices.

Establish a timetable for actions to prepare an initial evaluation of tax expenditure in September 2012.
Completed. One-third of tax audit programming is based on the use of tax-related information.

In progress. To be improved

To be done

To be done. Training needed.

To be improved. Training needed.

PAMORI project suspended. Expected to be resumed before end-2013.

Completed in part. To be improved

Completed

Completed 


\section{Annex 2}

\section{Implementation Status of Recommendations of the 2008 FAD Mission on Customs Administration}

\begin{tabular}{|c|c|}
\hline Key measures recommended & Status \\
\hline \multicolumn{2}{|c|}{ PRIORITY REFORMS FOR CUSTOMS ADMINISTRATION (2008-09) } \\
\hline $\begin{array}{l}\text { Framework for services and implementation of reforms } \\
\text { - Adapt the strategic plan and detail actions and monitoring indicators } \\
\text { - Establish a framework for change management } \\
\text { - Implement a management information system } \\
\text { - Continue automation efforts } \\
\text { - Apply the internal control plan } \\
\text { - Organize the system of supervisory controls }\end{array}$ & $\begin{array}{l}\text { Completed } \\
\text { Completed } \\
\text { Not done } \\
\text { In progress } \\
\text { Completed } \\
\text { Completed }\end{array}$ \\
\hline $\begin{array}{l}\text { Human resources } \\
\text { - Prepare a human resources management plan } \\
\text { - Develop and implement the personnel redeployment plan } \\
\text { - Provide for control of personnel assigned to Customs } \\
\text { - Provide continuing training adapted to requirements } \\
\text { - Implement a detection mechanism for disciplinary cases }\end{array}$ & $\begin{array}{l}\text { Delayed by events } \\
\text { In progress } \\
\text { Partially completed } \\
\text { Partially completed } \\
\text { Completed }\end{array}$ \\
\hline $\begin{array}{l}\text { Procedures } \\
\text { - Rationalize import clearance procedures }\end{array}$ & In progress \\
\hline $\begin{array}{l}\text { Control and prevent fraud } \\
\text { - Redeploy resources to post-clearance inspection and mobile brigades } \\
\text { - Organize the risk analysis to be used for selection of channels in } \\
\text { ASYCUDA } \\
\text { - Improve mechanisms for coordination and exchange with BIVAC }\end{array}$ & $\begin{array}{l}\text { First step completed } \\
\text { In progress - delayed by } \\
\quad \text { events } \\
\text { Completed }\end{array}$ \\
\hline $\begin{array}{l}\text { Administrative management of exemptions } \\
\text { - Implement a program to verify final destination of exempt goods based } \\
\text { on verification of consistency between inputs and beneficiary activities } \\
\text { - Institute an annual report on the status of goods exempted during the } \\
\text { three preceding years } \\
\text { - Prepare a detailed annual report on the execution of any exceptional tax } \\
\text { measure. }\end{array}$ & $\begin{array}{l}\text { Completed } \\
\text { In progress } \\
\text { In progress }\end{array}$ \\
\hline $\begin{array}{l}\text { Organization and missions of offices } \\
\text { - Adjust the offices' functions and authorities. }\end{array}$ & Completed \\
\hline
\end{tabular}




\section{Annex 3}

\section{Estimated import duty and tax exemptions 2011 - May 31, 2013}

\begin{tabular}{|r|l|r|r|r|}
\hline \multirow{2}{*}{ Exemption category } & \multicolumn{2}{|c|}{ Duties and taxes exempted (CFAF millions) } \\
\cline { 3 - 4 } & & $\mathbf{2 0 1 1}$ & $\mathbf{2 0 1 2}$ & As at May 31, 2013 \\
\hline 1 & Investment Code & $11,275.2$ & $11,816.1$ & $5,763.8$ \\
\hline 2 & Mining and Petroleum Code & $26,009.9$ & $27,785.1$ & $18,005.9$ \\
\hline 3 & Grants and assistance & $3,231.4$ & $6,845.4$ & $3,521.5$ \\
\hline 4 & NGOs & $1,984.1$ & $1,961.3$ & $1,011.9$ \\
\hline 5 & Diplomats and similar persons & $6,271.0$ & $5,168.8$ & $4,194.8$ \\
\hline 6 & $\begin{array}{l}\text { Externally financed projects, } \\
\text { public contracts, and international } \\
\end{array}$ & & & \\
\hline 7 & agreements & $17,079.6$ & $19,159.8$ & $5,830.0$ \\
\hline & Other & $43,509.3$ & $43,960.3$ & $9,780.5$ \\
\hline
\end{tabular}

Source: DGD 


\section{Annex 4}

\section{Sample provisions of customs legislation}

\section{Enforced payment}

"Any goods reported for exportation under section 95 or imported by or on behalf of a debtor are subject to a lien for the amount owed by the debtor and may be detained by an officer at the expense of the debtor until that amount is paid"

Source: Article 97.25 (1) Canadian Customs Act (L.R.C. (1985), ch.1 (2 ${ }^{\text {nd }}$ suppl.))

\section{$\underline{\text { Right of appeal }}$}

Provisions that could be incorporated into the Customs Code:

Article

"Any person shall be entitled to appeal decisions by customs authorities concerning the application of customs laws that directly and individually concern him or her. The right of appeal shall be exercised in the form of a written request addressed to the Director General of Customs explaining the grounds of the dispute. The appeal must be submitted within two months after the date when the individual was informed of the challenged decision. The Director General of Customs shall be required to provide a written, reasoned response within two months following receipt of the request. The response may overturn, uphold, or modify the decision or request additional information. In the latter case, the final response shall be provided within one month from receipt of the additional information requested." 